\title{
Conceptus development and transcriptome at preimplantation stages in lactating dairy cows of distinct genetic groups and estrous cyclic statuses
}

\author{
E. S. Ribeiro, ${ }^{*} \dagger^{1}$ A. P. A. Monteiro, ${ }^{*}$ R. S. Bisinotto, ${ }^{*} \dagger^{2}$ F. S. Lima, ${ }^{*} \dagger^{3}$ L. F. Greco, ${ }^{\star} \dagger$ A. D. Ealy, $\ddagger$ \\ W. W. Thatcher, ${ }^{*} \dagger$ and J. E. P. Santos ${ }^{*} \dagger^{4}$ \\ *Department of Animal Sciences, University of Florida, Gainesville 32611 \\ †DH Barron Reproductive and Perinatal Biology Research Program, University of Florida, Gainesville 32611 \\ ‡Department of Animal and Poultry Sciences, Virginia Polytechnic Institute and State University, Blacksburg 24060
}

\begin{abstract}
The objectives were to compare development and transcriptome of preimplantation conceptuses $15 \mathrm{~d}$ after synchronized ovulation and artificial insemination (AI) according to the genetic background of the cow and estrous cyclicity at the initiation of the synchronization program. On d $39 \pm 3$ postpartum, Holstein cows that were anovular $(\mathrm{HA} ; \mathrm{n}=10)$, Holstein cows that were estrous cyclic ( $\mathrm{HC} ; \mathrm{n}=25)$, and Jersey/Holstein crossbred cows that were estrous cyclic $(\mathrm{CC} ; \mathrm{n}=25)$ were randomly selected in a grazing herd and subjected to the Ovsynch protocol. All cows were inseminated on d $49 \pm 3$ postpartum, which was considered study d 0 . Blood was sampled and analyzed for concentrations of progesterone, estradiol, insulin, and insulin-like growth factor 1 (IGF-1) on study d $-10,-3,-1,7$, and 15 relative to AI. On study d 15 , uteri were flushed and recovered fluid had IFN- $\tau$ concentrations measured and subjected to metabolomic analysis. Morphology of the recovered conceptuses was evaluated, and mRNA was extracted and subjected to transcriptome microarray analysis. Compared with HC, CC presented greater concentrations of progesterone and estradiol in plasma, with corpora lutea and preovulatory follicles of similar size. Conceptuses from CC were larger, tended to secrete greater amounts of IFN- $\tau$, and had greater transcript expression of peroxisome proliferator-activated receptor gamma $(\mathrm{PPAR} \gamma)$, an important transcription factor that coordinates lipid metabolism and elongation at preimplantation development. In addition, pregnant
\end{abstract}

Received August 26, 2015.

Accepted February 9, 2016.

${ }^{1}$ Current address: Department of Animal Biosciences, University of Guelph, Guelph, ON, Canada N1G 2W1.

${ }^{2}$ Current address: Department of Veterinary Population Medicine, University of Minnesota, St. Paul, MN 55108.

${ }^{3}$ Current address: Department of Veterinary Clinical Medicine, University of Illinois Urbana-Champaign, Urbana, IL 61802.

${ }^{4}$ Corresponding author: Jepsantos@ufl.edu
CC had greater concentrations of anandamide in the uterine flush, which might be important for elongation of the conceptus and early implantation. Conceptuses from HA were also longer and secreted greater amounts of IFN- $\tau$ than conceptuses from HC, likely because of the distinct progesterone profiles before and after AI. Nonetheless, anovular cows had reduced concentrations of IGF-1 in plasma, and their conceptuses presented remarkable transcriptomic differences. Some of the altered transcripts suggest that conceptus cells from anovular cows might be under greater cellular stress and presented markers suggesting increased apoptosis and autophagy, which could lead to increased mortality after d 15 of development. Estrous cyclicity had more impact on transcriptome of bovine conceptus than genetic background, and the developmental changes observed during the preimplantation period might be linked to differences in fertility among groups.

Key words: conceptus development, crossbreeding, dairy cow, estrous cyclicity

\section{INTRODUCTION}

Anovulation is a normal and temporary physiological condition of most mammals including dairy cows during early postpartum. It is characterized by lack of regular estrous cycles and ovulation, although follicle growth is still present (Wiltbank et al., 2002). Time for resumption of estrous cyclicity postpartum varies among cows and is directly associated with nutritional balance in the first weeks of lactation (Butler, 2003). As consequence, 18 to $43 \%$ of dairy cows remain anovular at the end of the voluntary waiting period, constituting an important problem in achieving adequate reproductive performance in dairy herds (Rhodes et al., 2003; Santos et al., 2009).

Adoption of timed AI programs maximizes submission to AI and lessens the problem of anovular cows reducing reproductive performance. Nevertheless, pregnancy per AI (P/AI) of anovular cows after synchro- 
nized estrus or ovulation is reduced compared with that of estrous cyclic herdmates (McDougall et al., 2005; Santos et al., 2009). Thus, anovulation impairs pregnancy rate and reproductive performance even when timed AI programs are implemented. It has been shown that reduced fertility results from impaired capability to establish or maintain pregnancy (Bisinotto et al., 2010). Nonetheless, timing and biology of the events leading to impaired zygote development are unknown.

Genetics is an important component influencing several traits related to production, health, and reproduction in dairy cows (Egger-Danner et al., 2015). One strategy that has been used in commercial herds is crossbreeding of complementary pure breeds not only to obtain a desired phenotype, but also to reduce inbreeding and maximize heterosis (Weigel and Barlass, 2003). The crossbreeding between Holstein and Jersey cattle, for instance, is common and aims to combine the high milk volume yield of Holsteins with the high solids content in milk of Jerseys. In addition, improvements in reproduction have been reported with this crossbreeding strategy (Heins et al., 2008; Ribeiro et al., 2011), and might be a result of the heterosis generated by the combination of the 2 distinct genetic backgrounds. Nonetheless, the effect of crossbreeding or heterosis on early developmental biology remains largely unknown.

We hypothesized that both anovulation at the onset of synchronization of ovulation protocol and crossbreeding affect conceptus development in dairy cows and would reflect in differences in fertility. The first study aimed to evaluate fertility data to further document the effect of estrous cyclicity status at the beginning of the synchronization program and genetic background of the cow on reproductive performance at first AI postpartum. The second study aimed to compare preimplantation conceptus development to the initial elongation stages and their transcriptome in lactating cows with distinct combinations of genetic background and estrous cyclicity to elucidate some of the biology involved in their fertility differences.

\section{MATERIALS AND METHODS}

All procedures involving cows were approved by the animal care and use committee of the University of Florida (Gainesville).

\section{Study 1: Fertility Data}

This study followed a prospective cohort design. Data comprising breed of cow, estrous cyclicity at the initiation of the synchronization program, and $\mathrm{P} / \mathrm{AI}$ at the first AI postpartum were collected in 3 seasonally calving farms. Data were collected in 2 breeding seasons on farms $\mathrm{A}$ and $\mathrm{B}$, and in 1 breeding season on farm C. Dairies were located in north central Florida and used similar cow genetics and management practices. The herds were composed of Holstein $(\mathbf{H})$, Jersey $(\mathbf{J})$, and Holstein/Jersey crossbreds, mostly $\mathrm{F}_{1}(50 \mathrm{H}: 50 \mathrm{~J})$ and $\mathrm{F}_{2}$ (25H:75J or $\left.75 \mathrm{H}: 25 \mathrm{~J}\right)$ generations of crossbreeding between Holstein and Jersey genetics. A total of 3,196 lactating cows (737 Holsteins, 1,825 Holstein/Jersey crossbreds, and 634 Jerseys) were enrolled in the study. Primiparous cows represented $31 \%$ and multiparous cows represented $69 \%$ of the study animals. The mean $( \pm \mathrm{SD})$ lactation number was $2.2 \pm 1.1$. The different genetic groups were represented in all herds and breeding seasons, managed in a pasture-based system, and supplemented with concentrates (Ribeiro et al., 2011). Cows were milked twice a day and the average milk production per cow across the different herds and breeds of the cows was approximately $6,000 \mathrm{~kg} /$ lactation.

Cows in all herds were enrolled in a preplanned breeding season and received timed AI on the first day of breeding (study d 0). For that, the estrous cycle was presynchronized and then cows were subjected to synchronization of ovulation programs. The presynchronization consisted of 2 injections of $\mathrm{PGF}_{2 \alpha}$ (Lutalyse sterile solution; $5 \mathrm{mg} / \mathrm{mL}$ of dinoprost tromethamine, Zoetis, Florham Park, NJ) administered $14 \mathrm{~d}$ apart. The synchronization protocol was initiated 10 to $12 \mathrm{~d}$ after the second $\mathrm{PGF}_{2 \alpha}$ of the presynchronization and consisted of $\mathrm{GnRH}$ (Cystorelin; $50 \mu \mathrm{g} / \mathrm{mL}$ of gonadorelin diacetate tetrahydrate, Merial Ltd., Iselin, NJ) on $\mathrm{d}-8, \mathrm{PGF}_{2 \alpha}$ on $\mathrm{d}-3$ and -2 , and $\mathrm{GnRH}+\mathrm{AI}$ on d 0 . Cows were artificially inseminated using sires with North American genetics, 20 Jerseys, 9 Holsteins, and 4 Swedish Red sires. On d -3 , tailheads were painted using oil-based tail paint for detection of estrus based on rubbed off tails on the day of AI. On the day of the first GnRH injection of the timed AI program, blood was sampled and analyzed for concentration of progesterone. Cows with progesterone concentration $\geq 1.0 \mathrm{ng} /$ $\mathrm{mL}$ were considered estrous cyclic and those with progesterone concentration $<1.0 \mathrm{ng} / \mathrm{mL}$ were considered anovular. Mean and median DIM at first AI were 117 and 102, respectively.

Pregnancy was diagnosed in all cows on d 30 via ultrasonography of the uterus and its contents, and was characterized by visualization of an embryo with heartbeat. Cows diagnosed as pregnant on d 30 were reexamined by transrectal palpation $35 \mathrm{~d}$ later. Pregnancy per AI was calculated as the number of pregnant cows on $\mathrm{d} 30$ and 65 after an insemination divided by the total number of cows inseminated. Pregnancy loss was calculated as the number of cows that lost pregnancy between gestation d 30 and 65 divided by the number of pregnant cows on d 30 . 


\section{Study 2: Preimplantation Conceptus Development}

Cows and Management. This study was conducted in a seasonally calving grazing dairy located in north central Florida with the same genetics and general management described above for study 1 . The farm milked approximately 1,200 cows twice daily and the rolling herd average for milk yield during the study period was $6,500 \mathrm{~kg} / \mathrm{cow}$.

Study Design. This study followed a prospective cohort study design. Four weekly cohorts of purebred Holstein and crossbred Holstein/Jersey cows had their ovaries examined by ultrasonography (Easy Scan, BCF Technology, Livingston, UK) using a $7.5-\mathrm{MHz}$ linear transducer on d 29 and $39 \pm 3$ postpartum. Presence of a corpus luteum (CL) in at least 1 of the 2 ultrasonographic examinations characterized an estrous cyclic cow, whereas lack of CL in both examinations characterized an anovular cow. Three groups were then formed (Figure 1): Holstein anovular cows (HA), Holstein cyclic cows (HC), and crossbred cyclic cows (CC). Sixty lactating cows were used in the study (HA $=10 ; \mathrm{HC}=25 ; \mathrm{CC}=25)$. Cows were enrolled in 4 consecutive weeks, and random selection of cows presenting the predefined conditions was used.

Synchronization of the Estrous Cycle and Ovulation. All cows received an injection of $25 \mathrm{mg}$ of $\mathrm{PGF}_{2 \alpha}$ on d $29 \pm 3$ postpartum. Ten days later, cows were enrolled in an Ovsynch protocol. For the 2 cyclic groups, only cows with a functional CL when the Ovsynch started were used. Cows received an injection of $100 \mu \mathrm{g}$ of $\mathrm{GnRH}$ on d $39 \pm 3$ postpartum, an injection of $25 \mathrm{mg}$ of $\mathrm{PGF}_{2 \alpha}$ on d $46 \pm 3$ postpartum, and a final injection of $100 \mu \mathrm{g}$ of $\mathrm{GnRH}$ on $\mathrm{d} 48 \pm 3$ postpartum, $56 \mathrm{~h}$ after the $\mathrm{PGF}_{2 \alpha}$ injection. All cows were inseminated using a single Holstein sire on d $49 \pm$ 3 postpartum.

Samples and Data Collection. Ovaries were evaluated by ultrasonography concurrent with blood sampling on $\mathrm{d}-10$ (a.m.), -3 (a.m.), -1 (p.m.), 7 (a.m.), and 15 (a.m.) relative to AI. Follicle and CL diameters and ovulatory responses to hormonal treatments were evaluated using an ultrasound equipped with a 7.5$\mathrm{MHz}$ linear-array transducer. Blood was sampled by puncture of the coccygeal vessels into evacuated tubes containing $\mathrm{K}_{2}$ EDTA (Becton, Dickinson, Franklin Lakes, NJ). Samples were placed immediately in ice and centrifuged at 2,000 $\times g$ for $15 \mathrm{~min}$, and aliquots of plasma were frozen at $-25^{\circ} \mathrm{C}$ for later analyses. All activities with cows were performed after the morning milking, except for those on $\mathrm{d}-1$, which were performed after the evening milking.

On d 15, the uterine horn ipsilateral to the CL was transcervically flushed for conceptus collection. Epidural anesthesia was used and the vulva and vagina were thoroughly cleansed. Initially, $20 \mathrm{~mL}$ of PBS (0.01 M

Establishment of 3 groups based on

breed of the cow and estrous cyclicity at first GnRH:

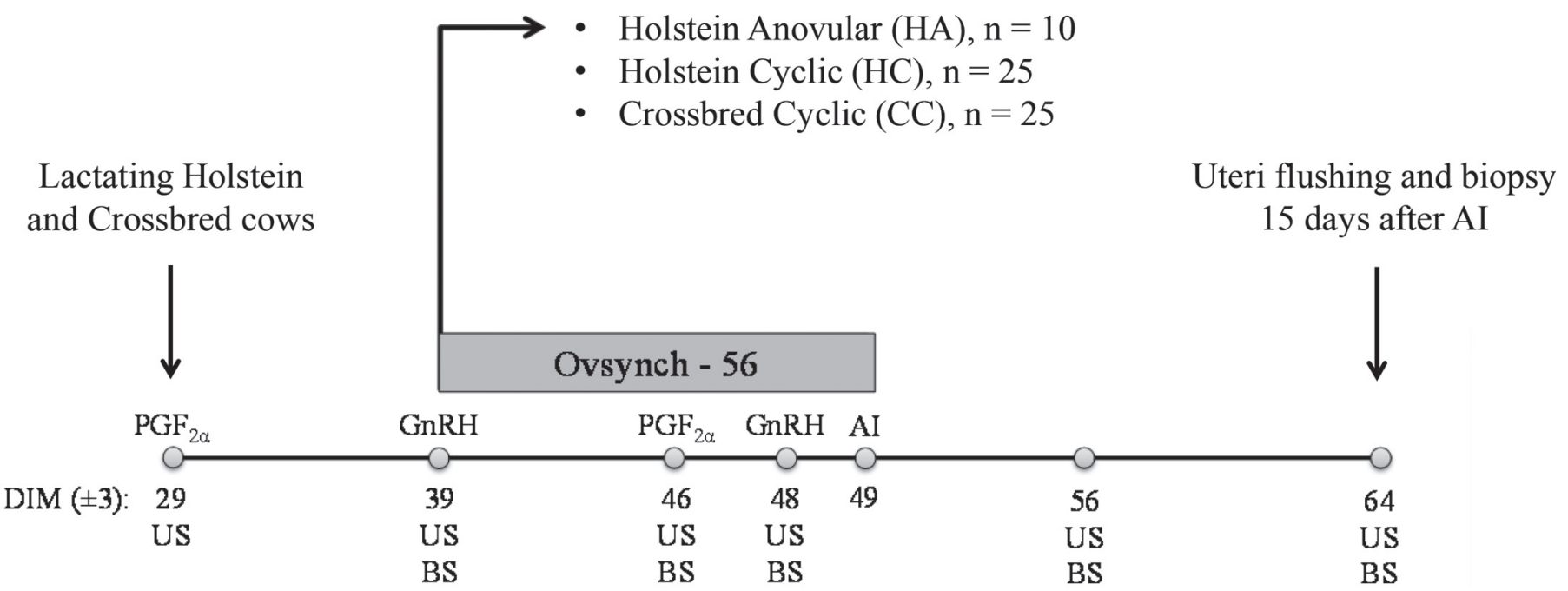

Figure 1. Diagram of activities for study 2. Ultrasonographic examination of the ovaries was used to determine the estrous cyclic status. Ovarian follicle and corpus luteum (CL) dynamics were evaluated by ultrasound. Uteri were flushed on d 15 after AI for recovery of conceptuses and uterine fluid, and endometrial tissue was collected for biopsy. Blood samples were collected for evaluation of concentration of progesterone, estradiol, IGF-1, and insulin in plasma. BS = blood sample; US = ultrasonography of ovaries. 
phosphate buffer and $0.154 M$ sodium chloride, $\mathrm{pH}$ 7.4) with $0.1 \%$ (vol/vol) of polyvinyl alcohol (PBS+PVA) solution was infused using a $60-\mathrm{mL}$ plastic syringe (Becton, Dickinson) connected to a 20 to 24 French silicone-coated latex Foley catheter (Bard, Covington, GA). The fluid infused was recovered into the same syringe used for infusion and then examined in a Petri dish under stereoscope for location of conceptus tissue. Up to 5 additional flushings were performed if no conceptus tissue was recovered. The recovered conceptuses were washed in fresh drops of PBS+PVA, had their length measured, and were snap-frozen in liquid $\mathrm{N}_{2}$ and later stored at $-80^{\circ} \mathrm{C}$ until nucleic acid extraction. Conceptuses $<5 \mathrm{~mm}$ in length were classified as ovoid, whereas those $>5 \mathrm{~mm}$ long were classified as elongated. The uterine fluid of the first flushing was placed in conical tubes in ice and later centrifuged at 2,000 $\times$ $g$ at $4^{\circ} \mathrm{C}$ for $15 \mathrm{~min}$. The supernatant was collected, homogenized, aliquoted, and stored at $-80^{\circ} \mathrm{C}$ for later analyses of fluid composition.

Transcriptome Analysis of Conceptus Cells. Nucleic acids, mRNA and genomic DNA from conceptus cells were extracted using the AllPrep DNA/RNA kit (Qiagen, Germantown, MD) according to manufacturer instructions. Quality and integrity of purified mRNA were evaluated using Nanodrop (Thermo Fisher Scientific, Waltham, MA) and Bioanalyzer (Agilent 2100 Bioanalyzer, Agilent Technologies, Santa Clara, CA) analyses. A subsample of only elongated conceptuses from each group (6 $\mathrm{HC}, 6 \mathrm{HA}$, and $6 \mathrm{CC}$ ) with ratio of absorbance at 260 to $280 \mathrm{~nm}$ between 1.95 and 2.1, and with RNA integrity number $>7.5$ were selected randomly within each experimental group and subjected to transcriptome analysis using the GeneChip Bovine Genome Array (Affymetrix, Santa Clara, CA) at the Interdisciplinary Center for Biotechnology Research Gene Expression and Genotyping Core at University of Florida (Gainesville). All microarray sample preparation used the GeneChip 3' In Vitro Transcription Express kit (Affymetrix), and reactions were performed following the manufacturer's protocols. Briefly, cDNA was synthesized from $200 \mathrm{ng}$ of total RNA and template for in vitro transcription during which a biotin-modified nucleotide was incorporated. The biotin-labeled amplified RNA was then purified and fragmented. Samples were hybridized with rotation at $45^{\circ} \mathrm{C}$ for $16 \mathrm{~h}$ to the Affymetrix GeneChip Bovine arrays. The arrays were washed and stained with the reagents supplied in GeneChip Hybridization Wash and Stain kit (Affymetrix) on an Affymetrix Fluidics Station 450, and scanned with a GeneChip 7G Scanner (Affymetrix).

Concentration of IFN- $\tau$ in the Uterine Flushing. Concentrations of IFN- $\tau$ in the uterine fluid samples were determined based on their ability to prevent vesicular stomatitis virus (VSV)-induced lysis of Madin-Darby bovine kidney (MDBK) cells and using recombinant $\mathrm{hIFN}-\alpha$ (100 IU/ $\mu \mathrm{L}$; EMD Biosciences Inc., Gibbstown, NJ) as standard (Rodina et al., 2009). Briefly, $100 \mu \mathrm{L}$ of Dulbecco's modified Eagle medium (DMEM; Invitrogen, Grand Island, NY) supplemented with 10\% fetal bovine serum (FBS; HyClone, Logan, UT) were pipetted into each well of 96-well plates. Then, $50 \mu \mathrm{L}$ of either standard or uterine fluid sample was added to the first well of each row and serial 1:3 dilutions were performed until the last well of the row. The standard was evaluated in every plate and each sample was assayed in duplicate. Fifty microliters of MDBK cell preparation was then added to each well and incubated at $37^{\circ} \mathrm{C}$ in $5 \% \mathrm{CO}_{2}$ for $24 \mathrm{~h}$. Medium was then removed and cells were challenged with VSV by adding $50 \mu \mathrm{L}$ of VSV solution and incubating at $37^{\circ} \mathrm{C}$ in $5 \% \mathrm{CO}_{2}$ for $1 \mathrm{~h}$. The VSV solution was then removed and $100 \mu \mathrm{L}$ of DMEM with $10 \%$ FBS was added for additional $20 \mathrm{~h}$ of incubation at $37^{\circ} \mathrm{C}$ in $5 \% \mathrm{CO}_{2}$. Medium was then removed and cells were fixed with $70 \%$ ethanol and stained with $0.5 \%$ gentian violet. Inhibition of VSV-induced lysis of MDBK cells was then assessed visually and compared with standard activity. Concentration was then calculated based on previously described activity of bovine IFN- $\tau\left(8.03 \times 10^{8} \mathrm{IU} / \mathrm{mg}\right.$; Rodina et al., 2009). The sensitivity of the assay was $1 \mathrm{pg} / \mathrm{mL}$ and the intra- and inter-assay coefficients of variation were, respectively, 1.0 and $1.7 \%$.

Metabolomics of Uterine Fluid. Histotroph composition in pregnant cows was evaluated by metabolomics of uterine fluid. A total of 18 uterine fluid samples from pregnant cows $(6 \mathrm{HA}, 6 \mathrm{HC}$, and $6 \mathrm{CC})$ were subjected to liquid chromatography and mass spectrophotometry (LC-MS) in the Southeast Center for Integrated Metabolomics at the University of Florida (Gainesville). Uterine fluid samples used for metabolomics were from the same flushings that recovered conceptuses used for transcriptome of conceptus cells.

Analyses were performed on a Thermo Q-Exactive High Resolution Mass Spectrometer coupled with a Dionex UHPLC and autosampler (Thermo Fisher Scientific Inc., Waltham, MA). The instrument runs both positive and negative ion modes with heated electrospray ionization. Mass resolution was 70,000 at $m / z 200$ with mass accuracy of $<5 \mathrm{ppm}$ in positive mode and $<10 \mathrm{ppm}$ in negative mode. Separation of metabolites was achieved on an Ace C18-PFP column $(100 \times 2.1$ mm, $2 \mu \mathrm{m}$; Advanced Chromatography Technologies, Aberdeen, UK) with $0.1 \%$ formic acid in water as mobile phase $\mathrm{A}$ and acetonitrile as mobile phase $\mathrm{B}$ with a column temperature of $25^{\circ} \mathrm{C}$. 
Sample preparation was performed by mixing 100 $\mu \mathrm{L}$ of each thawed uterine fluid sample with $20 \mu \mathrm{L}$ of internal standard mix (creatine-D3, L-leucine-D10, L-tryptophan-D3, and caffeine-D3) and $800 \mu \mathrm{L}$ of 8:1:1 acetonitrile:methanol:acetone solution. Samples were then vortexed for $10 \mathrm{~min}$ and cooled in a refrigerator for $30 \mathrm{~min}$. The tubes were centrifuged at 20,000 $\times g$ for $10 \mathrm{~min}$ to pellet the protein. The supernatant was then transferred to a new tube and dried with $\mathrm{N}_{2}$. The dried material was reconstituted by adding $100 \mu \mathrm{L}$ of $0.1 \%$ formic acid in LC-MS grade water. Flow rate was set to $350 \mu \mathrm{L} / \mathrm{min}$ with a total run time of $20 \mathrm{~min}$. A total of $2 \mu \mathrm{L}$ of each sample was injected for positive ion mode analysis and $4 \mu \mathrm{L}$ was injected for negative ion mode analysis. The LC-MS data were processed using MZmine 2 software (Pluskal et al., 2010) for peak picking and alignment, and for generation of intensity tables for statistical analyses. An in-house-curated retention time metabolite library was first used to identify metabolites. We then used additional external databases such as the human metabolome database (www.hmdb.ca) to expand potential identifications.

Hormone Assays. The concentration of progesterone in plasma was evaluated on samples collected on $\mathrm{d}-10,-3,-1,7$, and 15 relative to AI; estradiol was evaluated on samples from $\mathrm{d}-3$ and -1 ; and IGF-1 and insulin were evaluated on samples from $\mathrm{d} 7$ and 15. Concentrations of progesterone were determined by RIA using a commercial kit (Coat-a-Count; Siemens Healthcare Diagnostics, Los Angeles, CA). Only cows with low progesterone concentration $(<1 \mathrm{ng} / \mathrm{mL})$ on $\mathrm{d}-1$ and high progesterone concentration $(\geq 1 \mathrm{ng} /$ $\mathrm{mL}$ ) on $\mathrm{d} 7$ and 15 remained in the final data set of the study. Concentrations of estradiol were evaluated using a commercial kit (Estradiol Double Antibody, Siemens Healthcare Diagnostics) and adjustments described by Ribeiro et al. (2012). Concentrations of total IGF-1 were determined by a commercial ELISA kit (Quantikine ELISA Human IGF-1 Immunoassay, R\&D Systems Inc., Minneapolis, MN) designed for human IGF-1 but with $100 \%$ cross-reactivity with bovine IGF1. Concentrations of insulin were determined using a commercial bovine ELISA kit (Mercodia Bovine Insulin ELISA, Mercodia AB, Uppsala, Sweden). At least 2 control samples of known hormone concentrations were included multiple times in all assays.

BCS and Diseases Postpartum. Cows were scored for body condition on a 1 to 5 scale with increments of 0.25 units $(1=$ emaciated, $5=$ obese; Ferguson et al., 1994) at calving and 35 d postpartum. From calving until the end of the study, cows were monitored for the diagnosis of clinical diseases, including metritis, mastitis, and digestive, respiratory, and locomotor problems.

\section{Statistical Analyses}

Except for the microarray data, statistical analyses were performed using the GLIMMIX procedure of SAS (version 9.3; SAS/STAT, SAS Institute Inc., Cary, NC) and fitting adequate data distribution. Continuous variables were analyzed by ANOVA, and binary variables were analyzed by logistic regression. For study 1, the statistical models included the effect of breed, estrous cyclicity, the interaction between breed and estrous cyclicity, farm, calendar year, parity, DIM at AI, and BCS at AI. For study 2, the statistical models included the effect of group as HC, HA, and CC. For repeated measures, models included the effect of time, the interaction between group and time, and the random effect of cow nested within group. The covariance structure that resulted in the smallest Bayesian information criterion was selected. Treatment differences with $P \leq$ 0.05 were considered significant and $0.05<P \leq 0.15$ were considered a tendency.

Microarray data were analyzed using Bioconductor packages (www.bioconductor.org) in $\mathrm{R}$ version 3.1.1 (The R Foundation for Statistical Computing Platform; R Core Team, 2014; https://www.r-project.org/ foundation/). Data were preprocessed using Gene Chip Robust Multi-Array function (Wu et al., 2004). The Limma package (Smyth, 2005) was then used to fit a linear model and to adjust variances by empirical Bayes adjustment according to Smyth (2004). Moderate $t$-test was performed for pairwise comparisons among breedcyclicity groups and probability values were adjusted for multiple testing using the Benjamini and Hochberg false discovery rate (Benjamini and Hochberg, 1995). Adjustment for multiple group comparisons was performed by using the Global method within the decideTests function in Limma. Differently expressed genes were considered when adjusted $P<0.05$ and fold change $\geq 1.5$. Networks, functional and causal analyses were performed using Qiagen's Ingenuity Pathway Analysis software (IPA, Qiagen, Redwood City, CA; www.qiagen.com/ingenuity). Emphasis was given to canonical pathways, predicted upstream regulators and predicted downstream effects with a z-score $(\boldsymbol{Z} \boldsymbol{S})<$ or $>2.0$ and overlap $P$-value $(\boldsymbol{O P})<0.05$. Information regarding algorithms and statistical methods used in causal analysis of IPA were described by Krämer et al. (2014). The final lists of differently expressed transcripts among breed-cyclicity groups were compared with the list of transcripts that have expression modified during elongation of the bovine conceptus reported by Ribeiro et al. (2016). Because the present study used only elongated conceptuses for transcriptome analysis, the results were compared with the list of transcripts 
for which expression changed during the tubular to filamentous transition.

Statistical analyses of metabolomics data were performed using the web server MetaboAnalyst 2.0 (www.metaboanalyst.ca; Xia et al., 2012). Analyses for positive and negative ion modes were run separately using the same approach. A table matrix of $m / z$ peak intensities with samples in columns and features in rows were generated for each ion mode and imported to MetaboAnalyst 2.0. Features with $50 \%$ or more missing data were excluded from analyses. The remaining missing values were replaced by half of the minimum value in the original data. Preanalysis filtering was then performed based on the interquartile range to remove variables that are unlikely to be of use when modeling the data. In total, $25 \%$ of the variables were removed at this step considering the default approach used for data sets with 500 to 1,000 variables. Data were then normalized by the sum method, log-transformed, and scaled by the auto-scaling method. Statistical significances among groups ( $\mathrm{HC}$ vs. $\mathrm{HA}, \mathrm{HC}$ vs. $\mathrm{CC}$, and $\mathrm{CC}$ vs. HA) were determined by ANOVA with Fisher's least significant difference post hoc adjustment. Orthogonal contrast was used to further explore the effect of anovulation ( $\mathrm{HC}+\mathrm{CC}$ vs. HA). Significance was declared when $P \leq 0.05$.

\section{RESULTS}

\section{Study 1: Fertility Data}

The prevalence of estrous cyclic cows in the study population was $82.9 \%(2,650 / 3,196)$, and it was affected $(P<0.01)$ by breed of the cow (Figure $2 \mathrm{~A})$. A greater proportion of crossbred cows were estrous cyclic compared with Holstein and Jersey (Figure 2A). In addition, the proportion of estrous cyclic cows tended $(P<$ 0.09 ) to be greater for Jersey compared with Holstein.

The proportion of cows pregnant on d 30 after AI was influenced $(P<0.01)$ by estrous cyclicity at the initiation of synchronization program and tended $(P$ $=0.08$ ) to be influenced by breed of the cow (Figure 2B). Compared with estrous cyclic cows, anovular cows had a smaller $(P<0.01) \mathrm{P} / \mathrm{AI}$ on d $30(33.9$ vs. $56.3 \%$; adjusted odds ratio $=0.40 ; 95 \% \mathrm{CI}=0.32$ to 0.49 ). Holstein cows had reduced $(P=0.03) \mathrm{P} / \mathrm{AI}$ on $\mathrm{d} 30$ compared with crossbred cows (41.5 vs. $48.2 \%$; adjusted odds ratio $=0.76 ; 95 \% \mathrm{CI}=0.60$ to 0.97 ), but neither differed from Jersey cows (44.9\%). Within estrous cyclic cows, crossbred cows had greater $(P<0.04) \mathrm{P} / \mathrm{AI}$ on d 30 compared with Holsteins and Jerseys (61.7 vs. 50.6 vs. $56.4 \%$, respectively; Figure 2B). No differences among genetic groups were observed within anovular cows, and the P/AI averaged $33.9 \%$. The effects of breed of the cow and estrous cyclicity at the initiation of the synchronization program on $\mathrm{P} / \mathrm{AI}$ on $\mathrm{d} 30$ were the same for $\mathrm{P} / \mathrm{AI}$ on $\mathrm{d} 65$. Estrous expression at AI was associated $(P<0.01)$ with $\mathrm{P} / \mathrm{AI}$ (Figure $2 \mathrm{C}$ ), and an interaction $(P<0.01)$ between estrous cyclicity and detection of estrus at AI was observed. The reduction in $\mathrm{P} / \mathrm{AI}$ in anovular cows was only observed in those not detected in estrus at AI. Moreover, anovular cows that did not express estrus tended $(P=0.06)$ to have greater incidence of pregnancy loss between 30 and 65 d of gestation than cyclic cows or anovular cows that displayed estrus (Figure 2C).

\section{Study 2: Preimplantation Conceptus Development}

Reproductive Outcomes. As expected, concentrations of progesterone in plasma on the days of injections of the first $\mathrm{GnRH}$ and $\mathrm{PGF}_{2 \alpha}$ of the Ovsynch were lower $(P<0.01)$ for HA compared with $\mathrm{HC}$ and $\mathrm{CC}$ (Table 1). Although no difference in concentration of progesterone in plasma was observed between $\mathrm{HC}$ and $\mathrm{CC}$ on the day of the first GnRH, CC had greater $(P$ $=0.02)$ concentrations of progesterone on the day of $\mathrm{PGF}_{2 \alpha}$. An interaction $(P<0.01)$ between group and day of sampling was also observed (Table 1 ).

Diameter of the dominant follicle on the days of the $\mathrm{PGF}_{2 \alpha}$ and second $\mathrm{GnRH}$ of the Ovsynch protocol was greater $(P<0.02)$ for HA compared with $\mathrm{HC}$ or CC, and no differences were observed between the latter 2 groups (Table 1$)$. There was an interaction $(P<0.01)$ between group and day of sampling for concentrations of estradiol in plasma. On the day of $\mathrm{PGF}_{2 \alpha}, \mathrm{HA}$ had greater $(P<0.02)$ concentrations of estradiol than $\mathrm{HC}$ and CC; however, on the day of second $\mathrm{GnRH}, \mathrm{CC}$ had greater $(P<0.01)$ concentrations of estradiol than $\mathrm{HC}$ and HA. Expression of estrus at AI was similar among the 3 groups and averaged $25.0 \%$ (Table 1 ).

Progesterone concentration in plasma on the day of the second GnRH of the Ovsynch protocol was similar among the 3 groups. Nonetheless, the concentrations of progesterone on d 7 and 15 after AI were smaller $(P<0.05)$ for HC compared with the other 2 groups (Table 1). Holstein anovular cows had larger $(P<0.05)$ luteal tissue volume on $\mathrm{d} 7$ and 15 than $\mathrm{HC}$ cows. We detected no difference in luteal tissue volume between $\mathrm{HC}$ and $\mathrm{CC}$.

Pregnancy per AI on d 15 based on detection of IFN- $\tau$ on uterine fluid was not affected by group, although CC approached a tendency $(P=0.12)$ to have greater $\mathrm{P} /$ AI compared with HC. Conceptuses tended $(P=0.08)$ to be longer for $\mathrm{HA}$ and $\mathrm{CC}$ groups compared with $\mathrm{HC}$ (Table 1). Conceptus length was smaller $(P=0.01)$ for $\mathrm{HC}$ compared with $\mathrm{HA}$ or $\mathrm{CC}$, in part because $\mathrm{HA}$ and $\mathrm{CC}$ had only elongated conceptuses, whereas $\mathrm{HC}$ 
had $27.3 \%$ ovoid conceptuses. Elongated conceptuses selected randomly for the microarray analysis, however, maintained similar differences in conceptus size as observed in the experimental population (Table 1). The concentration of IFN- $\tau$ in the uterine fluid was greater
$(P<0.01)$ for HA compared with $\mathrm{HC}$ and tended $(P$ $=0.08)$ to be greater for $\mathrm{CC}$ compared with $\mathrm{HC}$. No differences were observed between HA and CC.

Incidence of clinical diseases was similar among groups (Table 2). Body condition score at calving and
A $\square$ Holstein $\square$ Crossbred $\square$ Jersey

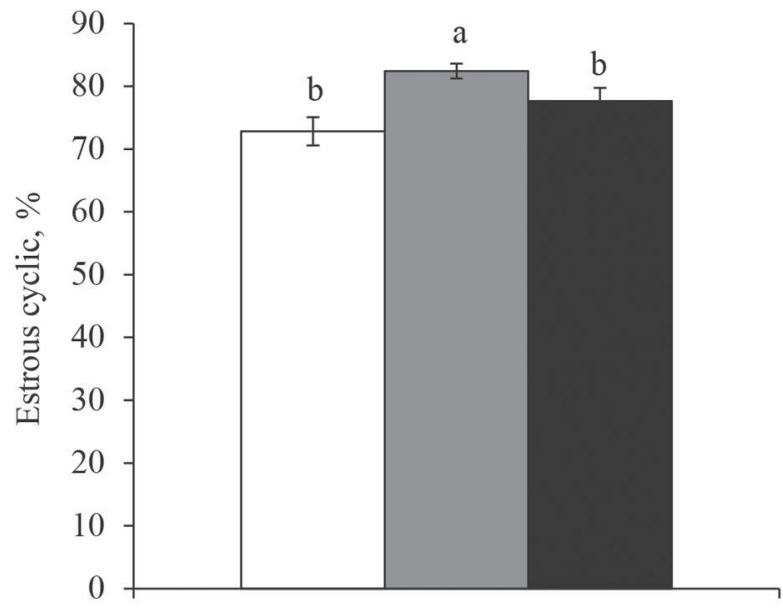

Breed of the cow
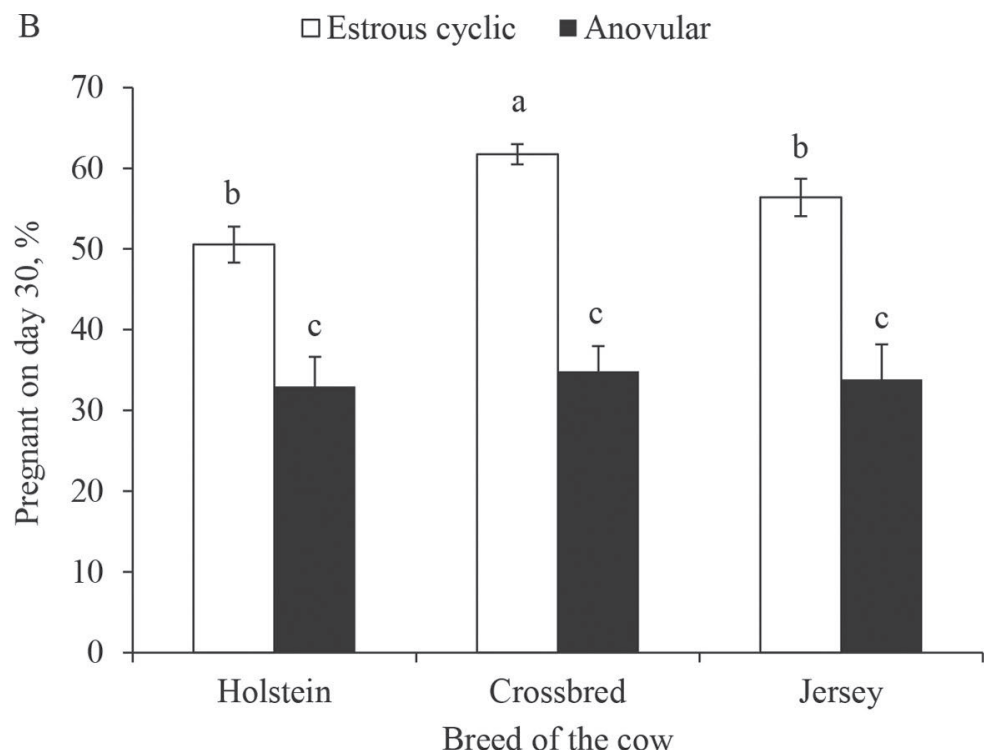

$\square$ Estrous cyclic/Estrus not expressed at AI

- Anovular/Estrus not expressed at AI

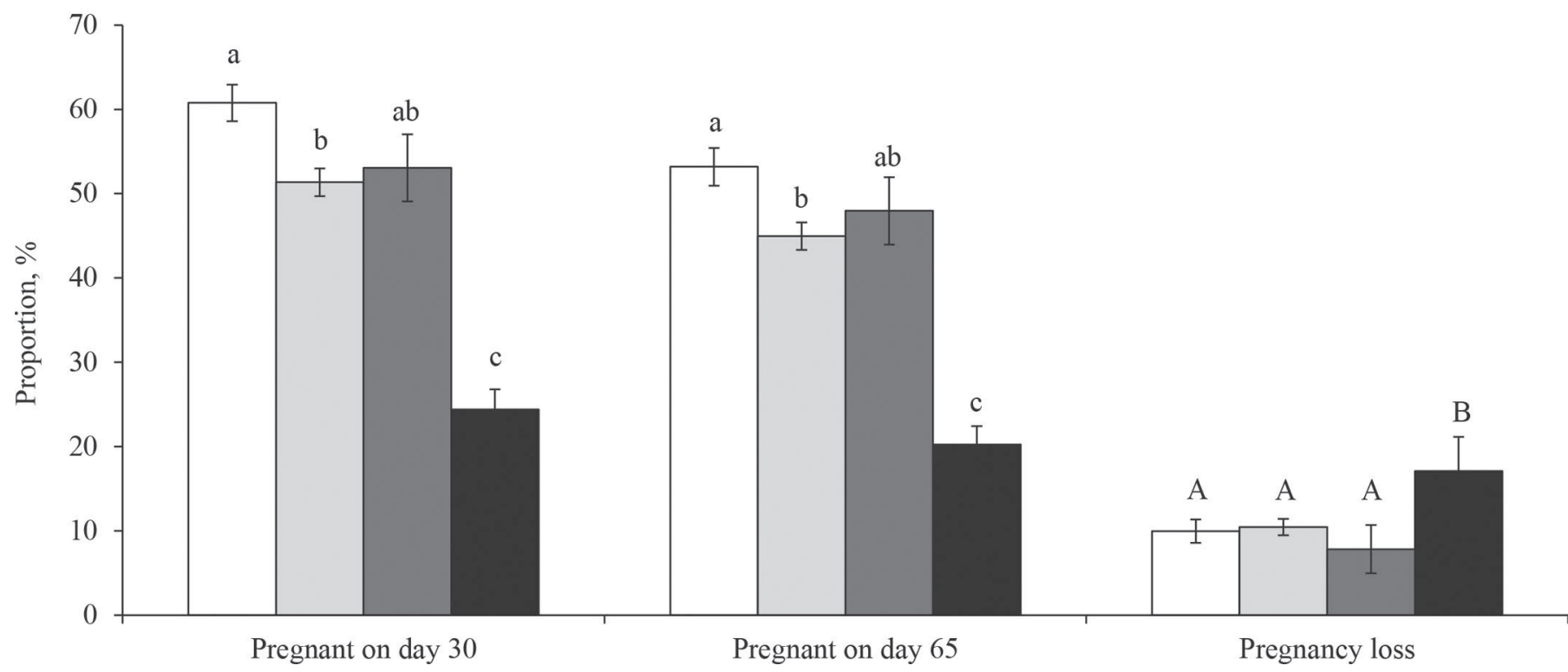

Figure 2. Reproductive outcomes from study 1: fertility data compilation. Data comprise information from 3,196 lactating cows (737 Holstein, 1,825 Holstein/Jersey crossbred, and 634 Jersey cows) subjected to synchronization of the estrous cycle and timed AI. (A) Proportion of estrous cyclic cows at the initiation of synchronization program according to the breed of the cow; (B) proportion of pregnant cows on $\mathrm{d}$ 30 after the first AI postpartum according to breed of the cows and estrous cyclic status at the initiation of the synchronization program; (C) proportion of pregnant cows on d 30 and 65 after first AI postpartum according to estrous cyclic status at the initiation of the synchronization program and expression of estrus at AI. Different letters above bars within a series represent statistical differences: ${ }^{\mathrm{a}, \mathrm{b}, \mathrm{c}} P \leq 0.05 ;{ }^{\mathrm{A}, \mathrm{B}} P=0.06$. Graphic bars represent the adjusted means and the error bars represent the SEM. 
on d 39 postpartum, however, was smaller $(P<0.01)$ for $\mathrm{HA}$ compared with $\mathrm{HC}$ and $\mathrm{CC}$, and the latter 2 groups did not differ (Table 2). Concentration of IGF-1 in plasma was smaller $(P<0.01)$ for HA compared with $\mathrm{HC}$, but neither group differed from CC (Table 2 ). On the other hand, the concentration of insulin in plasma was lesser $(P<0.01)$ for $\mathrm{CC}$ compared with HC, but neither group differed from HA (Table 2).

Transcriptome of Conceptus Cells. The comparison of HA with $\mathrm{HC}$ resulted in 500 transcripts differently expressed (Table 3; Supplementary Table S1A and Supplementary Figure S1A; http://dx.doi. org/10.3168/jds.2015-10315). Of those, 262 were upregulated and 238 were downregulated in HA. Moreover, 87 out of 500 transcripts were related to the transition from tubular to filamentous conceptus (Ribeiro et al., 2016). Of those 87 transcripts, 60 were upregulated and 27 were downregulated in HA compared with HC.
The main molecular and cellular functions associated with the differently expressed genes were molecular transport (35 transcripts; $O P<0.04$ ), lipid metabolism (24 transcripts; $O P<0.04$ ), and small molecule biochemistry (59 transcripts; $O P<0.04$ ). The main physiological system development and function were organismal development (46 transcripts; $O P<0.04$ ), skeletal and muscular system development and function (22 transcripts; $O P<0.04$ ), and embryonic development (43 transcripts; $O P<0.04$ ). The main diseases and disorders were connective tissue disorders (16 transcripts; $O P<0.04$ ), organismal injury and abnormalities $(249$ transcripts; $O P<0.04)$, and cancer $(248$ transcripts; $O P<0.04)$.

Among these categories, specific functional annotations with predicted increased activity included invasion of cancer cell lines $(O P=2.3 \mathrm{E}-02, Z S=2.2)$, $\beta$-oxidation of lipid $(O P=1.4 \mathrm{E}-02, Z S=2.2)$, and

Table 1. Ovarian dynamics, concentration of steroid hormones, pregnancy per AI, conceptus length, and concentration of IFN- $\tau$ in the uterine flush fluid in lactating cows with synchronized ovulation and uteruses flushed on d 15 after AI

\begin{tabular}{|c|c|c|c|c|}
\hline \multirow[b]{2}{*}{ Item } & \multicolumn{3}{|c|}{ Group $^{1}$} & \multirow[b]{2}{*}{$P$-value } \\
\hline & $\mathrm{HA}$ & $\mathrm{HC}$ & $\mathrm{CC}$ & \\
\hline $\begin{array}{l}\text { Progesterone prior luteolysis, }{ }^{*} \mathrm{ng} / \mathrm{mL} \\
\text { at first } \mathrm{GnRH} \text { of Ovsynch } \\
\text { at } \mathrm{PGF}_{2 \alpha} \text { of Ovsynch }\end{array}$ & $\begin{array}{l}0.09 \pm 0.73^{\mathrm{b}} \\
2.23 \pm 0.73^{\mathrm{c}}\end{array}$ & $\begin{array}{l}3.72 \pm 0.45^{\mathrm{a}} \\
7.99 \pm 0.43^{\mathrm{b}}\end{array}$ & $\begin{array}{l}3.86 \pm 0.46^{\mathrm{a}} \\
9.42 \pm 0.44^{\mathrm{a}}\end{array}$ & $<0.01$ \\
\hline $\begin{array}{l}\text { Diameter of dominant follicle, } \mathrm{mm} \\
\text { at } \mathrm{PGF}_{2 \alpha} \text { of Ovsynch } \\
\text { at second GnRH of Ovsynch }\end{array}$ & $\begin{array}{l}16.3 \pm 0.99^{\mathrm{a}} \\
23.5 \pm 0.99^{\mathrm{a}}\end{array}$ & $\begin{array}{l}13.2 \pm 0.62^{\mathrm{b}} \\
20.7 \pm 0.62^{\mathrm{b}}\end{array}$ & $\begin{array}{l}13.2 \pm 0.62^{\mathrm{b}} \\
19.1 \pm 0.62^{\mathrm{b}}\end{array}$ & $<0.01$ \\
\hline $\begin{array}{l}\text { Estradiol concentration, }{ }^{*} \mathrm{pg} / \mathrm{mL} \\
\text { at } \mathrm{PGF}_{2 \alpha} \text { of Ovsynch } \\
\text { at second } \mathrm{GnRH} \text { of Ovsynch }\end{array}$ & $\begin{array}{l}3.08 \pm 0.75^{\mathrm{a}} \\
4.83 \pm 0.71^{\mathrm{b}}\end{array}$ & $\begin{array}{l}0.77 \pm 0.47^{\mathrm{b}} \\
5.39 \pm 0.45^{\mathrm{b}}\end{array}$ & $\begin{array}{l}0.90 \pm 0.47^{\mathrm{b}} \\
7.11 \pm 0.45^{\mathrm{a}}\end{array}$ & 0.11 \\
\hline Expression of estrus at AI, \% (no./no.) & $40.0(4 / 10)$ & $20.0(5 / 25)$ & $24.0(6 / 25)$ & 0.48 \\
\hline $\begin{array}{l}\text { Progesterone after luteolysis, ng/mL } \\
\text { at second GnRH of Ovsynch } \\
\text { at d } 7 \text { after } \mathrm{AI} \\
\text { at d } 15 \text { after } \mathrm{AI}\end{array}$ & $\begin{array}{l}0.12 \pm 0.39 \\
4.08 \pm 0.39^{\mathrm{a}} \\
7.61 \pm 0.39^{\mathrm{a}}\end{array}$ & $\begin{array}{l}0.28 \pm 0.25 \\
3.03 \pm 0.25^{\mathrm{b}} \\
6.67 \pm 0.25^{\mathrm{b}}\end{array}$ & $\begin{array}{l}0.25 \pm 0.25 \\
4.02 \pm 0.25^{\mathrm{a}} \\
7.73 \pm 0.25^{\mathrm{a}}\end{array}$ & 0.02 \\
\hline $\begin{array}{l}\text { Luteal tissue volume, } \mathrm{cm}^{3} \\
\text { at d } 7 \text { after } \mathrm{AI} \\
\text { at d } 15 \text { after AI }\end{array}$ & $\begin{array}{l}12.6 \pm 1.26^{\mathrm{a}} \\
12.4 \pm 1.26^{\mathrm{a}}\end{array}$ & $\begin{array}{l}7.7 \pm 0.80^{\mathrm{b}} \\
9.4 \pm 0.80^{\mathrm{b}}\end{array}$ & $\begin{array}{c}9.4 \pm 0.80^{\mathrm{b}} \\
11.0 \pm 0.80^{\mathrm{ab}}\end{array}$ & 0.02 \\
\hline $\begin{array}{l}\text { Pregnancy based on IFN- } \tau,{ }^{2} \% \text { (no./no.) } \\
\text { Ovoid conceptus, }{ }^{3} \% \text { (no./no.) } \\
\text { Conceptus length, mm }\end{array}$ & $\begin{array}{r}70.0(7 / 10) \\
0.0(0 / 0)^{\mathrm{b}}\end{array}$ & $\begin{array}{l}64.0(16 / 25) \\
27.3(3 / 16)^{\mathrm{a}}\end{array}$ & $\begin{array}{c}84.0(21 / 25) \\
0.0(0 / 0)^{\mathrm{b}}\end{array}$ & $\begin{array}{l}0.28 \\
0.05\end{array}$ \\
\hline $\begin{array}{l}\text { All recovered intact } \\
\text { Used for microarray analysis } \\
\text { IFN- } \tau,{ }^{4} \mathrm{pg} / \mathrm{mL}(95 \% \mathrm{CI})\end{array}$ & $\begin{array}{l}47.8 \pm 8.75^{\mathrm{a}} \\
58.0 \pm 9.12^{\mathrm{a}} \\
2,830^{\mathrm{a}} \\
(762-10,511)\end{array}$ & $\begin{array}{c}9.4 \pm 5.83^{\mathrm{b}} \\
15.0 \pm 10.53^{\mathrm{b}} \\
149^{\mathrm{b}, \mathrm{B}} \\
(63-356)\end{array}$ & $\begin{array}{c}25.3 \pm 8.75^{\mathrm{a}} \\
25.3 \pm 9.12^{\mathrm{a}} \\
430^{\mathrm{b}, \mathrm{A}} \\
(202-917)\end{array}$ & $\begin{array}{r}0.01 \\
0.04 \\
<0.01\end{array}$ \\
\hline
\end{tabular}

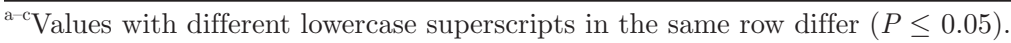

${ }^{\mathrm{A}, \mathrm{B}}$ Values with different uppercase superscripts in the same row differ $(P \leq 0.10)$.

${ }^{1} \mathrm{HA}=$ Holstein anovular; $\mathrm{HC}=$ Holstein cyclic; $\mathrm{CC}=$ crossbred cyclic. Estrous cyclicity was determined based on the presence of a corpus luteum in 1 of 2 ultrasound examinations of the ovaries $10 \mathrm{~d}$ apart, with the second examination on the day of the first GnRH of the Ovsynch protocol.

${ }^{2}$ Cows with detectable amounts of IFN- $\tau$ in the antiviral assay were considered pregnant. Data presented for continuous variables are LSM \pm SEM, except for the concentration of IFN- $\tau$, from which the $95 \%$ CI back-transformation from the logarithm distribution are reported.

${ }^{3}$ Conceptuses with length $<5 \mathrm{~mm}$.

${ }^{4}$ Concentration of IFN- $\tau$ in uterine ${ }_{\text {flushing }}$ of pregnant cows. Cows with no detectable IFN- $\tau$ were classified as nonpregnant and removed from this analysis.

*Interaction $(P \leq 0.05)$ between group and day. 
Table 2. Incidence of clinical diseases postpartum, BCS postpartum, and plasma concentrations of IGF-1 and insulin in lactating dairy cows subjected to synchronized ovulation and AI on d $49 \pm 3$ postpartum ${ }^{1}$

\begin{tabular}{|c|c|c|c|c|}
\hline \multirow[b]{2}{*}{ Item } & \multicolumn{3}{|c|}{ Group $^{2}$} & \multirow[b]{2}{*}{$P$-value } \\
\hline & HA & $\mathrm{HC}$ & $\mathrm{CC}$ & \\
\hline \multirow{3}{*}{$\begin{array}{l}\text { BCS, } 1-5 \text { scale } \\
\text { at calving } \\
\text { at d } 39 \pm 3 \text { postpartum }\end{array}$} & & & & $<0.01$ \\
\hline & $2.85 \pm 0.07^{\mathrm{b}}$ & $3.08 \pm 0.05^{\mathrm{a}}$ & $3.16 \pm 0.05^{\mathrm{a}}$ & \\
\hline & $2.73 \pm 0.07^{\mathrm{b}}$ & $2.93 \pm 0.05^{\mathrm{a}}$ & $2.97 \pm 0.05^{\mathrm{a}}$ & \\
\hline \multicolumn{5}{|l|}{ Metabolic hormones, ${ }^{3} \mathrm{ng} / \mathrm{mL}$} \\
\hline
\end{tabular}

${ }^{\mathrm{a}, \mathrm{b}}$ Values with different superscripts in the same row differ $(P<0.05)$.

${ }^{1}$ Data presented for BCS and metabolic hormone concentrations in plasma are LSM \pm SEM.

${ }^{2} \mathrm{HA}=$ Holstein anovular; $\mathrm{HC}=$ Holstein cyclic; $\mathrm{CC}=$ crossbred cyclic. Estrous cyclicity was determined based on the presence of a corpus luteum in 1 of 2 ultrasound examinations of the ovaries $10 \mathrm{~d}$ apart, with the second examination on the day of the first GnRH of the Ovsynch protocol.

${ }^{3}$ There were no interactions between group and day of blood sampling for IGF-1 and insulin.

apoptosis of neuroglia $(O P=3.1 \mathrm{E}-02, Z S=2.0)$. No specific function was significantly predicted $(Z S<-2.0)$ with decreased function. Potential upstream regulators of the differently expressed genes included prolactin $(O P=3.5 \mathrm{E}-02, Z S=2.4)$, peroxisome proliferatoractivated receptor gamma (PPARG; $O P=3.6 \mathrm{E}-03, Z S$ $=2.3)$, kruppel-like factor $15(\mathrm{KLF} 15 ; O P=3.5 \mathrm{E}-03$, $Z S=2.2)$, small ubiquitin-like modifier $2(O P=3.2 \mathrm{E}$ $03, Z S=2.0)$, and small ubiquitin-like modifier $3(O P$ $=3.2 \mathrm{E}-03, Z S=2.0)$ with predicted increased activity; enoyl-CoA, hydratase/3-hydroxyacyl CoA dehydrogenase (EHHADH; $O P=6.7 \mathrm{E}-06, Z S=-2.2$ ) and 173-hydroxysteroid dehydrogenase 4 (HSD17B4; OP = $4.8 \mathrm{E}-05, Z S=-2.2)$ with predicted decreased activity.

The most significant canonical pathways included urea cycle $(O P=5.9 \mathrm{E}-04$; transcripts: $A R G 2, A S L$, $A S S 1)$, myo-inositol biosynthesis $(O P=2.9 \mathrm{E}-03$; transcripts: IMPA1, IMPA2), and autophagy $(O P=$ 4.6E-03; transcripts: ATG4A, ATG4D, LAMP1, MA$P 1 L C 3 B, V P S 18)$. The top 10 upregulated genes based on fold change and having $\mathrm{HC}$ as reference group were CD36, CDKN1C, C15H11orf96, ASS1, IGFBP7, PAG2, GALM, PPARG, PRUNE2, and EVL, listed in decreasing order of absolute value in fold change. The top 10 downregulated genes based on fold change and having $\mathrm{HC}$ as reference were $A Q P 3, S L C 38 A 11$, FOLR1, PDGFRA, RNPC3, JAM2, TTC14, PPIF, INPP4B, and $D I S 3$, listed in decreasing order of absolute value in fold change.

Comparison of $\mathrm{CC}$ against $\mathrm{HC}$ resulted in only 42 transcripts differently expressed (Table 3; Supplementary Table S1B and Supplementary Figure S1A; http://dx.doi.org/10.3168/jds.2015-10315). From those transcripts, 10 were upregulated and 32 were downregulated in CC. Moreover, 4 out of 42 transcripts were related to the transition from tubular to filamentous conceptus reported by Ribeiro et al. (2016). From those 4 transcripts, 1 that had expression increased during elongation $(P P A R G)$ was upregulated in CC compared with HC. The other 3 whose expression decreased dur-

Table 3. Number of differently expressed transcripts in elongated conceptus cells

\begin{tabular}{|c|c|c|c|}
\hline \multirow[b]{2}{*}{ Item } & \multicolumn{3}{|c|}{ Group $^{1}$} \\
\hline & HA & $\mathrm{HC}$ & $\mathrm{CC}$ \\
\hline Number of elongated conceptus used & 6 & 6 & 6 \\
\hline \multicolumn{4}{|l|}{ Number of differently expressed transcripts } \\
\hline Upregulated & 262 & Reference & 10 \\
\hline Downregulated & 238 & Reference & 32 \\
\hline Total & 500 & Reference & 42 \\
\hline Related to tubular/filamentous transition ${ }^{2}$ & 87 & Reference & 4 \\
\hline Unrelated to tubular/filamentous transition ${ }^{2}$ & 413 & Reference & 38 \\
\hline
\end{tabular}

${ }^{1} \mathrm{HA}=$ Holstein anovular; $\mathrm{HC}=$ Holstein cyclic; $\mathrm{CC}=$ crossbred cyclic. Estrous cyclicity was determined based on the presence of a corpus luteum in 1 of 2 ultrasound examinations of the ovaries $10 \mathrm{~d}$ apart, with the second examination on the day of the first GnRH of the Ovsynch protocol.

${ }^{2}$ Contrasted with results published by Ribeiro et al. (2016), in which the transcriptome of tubular and filamentous conceptuses was compared. 
ing elongation (AOX1, F2R, and IL20RB) were downregulated in $\mathrm{CC}$ compared with $\mathrm{HC}$.

The few transcripts differentially expressed between $\mathrm{CC}$ and $\mathrm{HC}$ were related to the following molecular and cellular functions: cellular movement (5 transcripts; $O P$ $<0.05$ ), cell cycle $(2$ transcripts; $O P<0.05$ ), and cell death and survival (4 transcripts; $O P<0.05$ ). The only potential upstream regulator with predicted activity was LPS $(O P=8.3 \mathrm{E}-03, Z S=-2.0)$ and its activity was predicted to be reduced. The most significant canonical pathways involved with those genes were reelin signaling in neurons $(O P=6.2 \mathrm{E}-03$; transcripts: ARHGEF3, NDEL1), guanosine nucleotides degradation III $(O P=1.2 \mathrm{E}-02$; transcript: $A O X 1)$, and urate biosynthesis/inosine5'-phosphate degradation $(O P=$ 1.5E-02; transcript: $A O X 1)$. The top 10 downregulated genes based on fold change and having $\mathrm{HC}$ as reference were RNPC3, SLC13A2, SLC39A8, NR3C2, AOX1, GPRC5C, IL20RB, ARHGEF3, F2R, and $P R R 5 L$, listed in decreasing order of absolute value in fold change. The top 8 and only annotated genes that were upregulated based on fold change and having $\mathrm{HC}$ as reference were PPARG, BOLA-N, NDEL1, CCNY, RBM47, C1H8orf42, RPGRIP1, and KAT2B, listed in decreasing order of absolute value in fold change.

The comparison of anovular (HA) against estrous cyclic $(\mathrm{HC}+\mathrm{CC})$ cows resulted in 333 transcripts differently expressed (Supplementary Table S1C; http:// dx.doi.org/10.3168/jds.2015-10315). Of those, 192 were upregulated and 141 were downregulated in conceptuses from anovular cows. Moreover, 85 out of 333 transcripts were related to the transition from tubular to filamentous conceptus reported by Ribeiro et al. (2016). From those 85 transcripts, 61 whose expression increased during elongation were upregulated in HA compared with estrous cyclic cows. The other 24 whose expression decreased during elongation were downregulated in HA compared with estrous cyclic cows.

The main molecular and cellular functions associated with the differently expressed genes were cellular development (35 transcripts; $O P<0.04$ ), energy production (10 transcripts; $O P<0.04$ ), and lipid metabolism (27 transcripts; $O P<0.04)$. The main physiological system, development and function, included cardiovascular system development and function (24 transcripts; $O P<0.03)$, connective tissue development and function (24 transcripts; $O P<0.03$ ), and organ morphology (31 transcripts; $O P<0.03)$. The main diseases and disorders were cancer (84 transcripts; $O P<0.03$ ), organismal injury and abnormalities (96 transcripts; $O P<0.03$ ), and renal and urological disease (46 transcripts; $O P<0.03)$. Among these categories, specific function annotations with predicted increased activity included invasion of cancer cell lines $(O P=3.8 \mathrm{E}-03$,
$Z S=2.2)$, transport of lipid $(O P=8.1 \mathrm{E}-03, Z S=$ $2.2)$, and oxidation of lipid $(O P=5.6 \mathrm{E}-03, Z S=2.1)$. Specific function annotations with predicted decreased activity included concentration of phospholipid (OP $=1.9 \mathrm{E}-02, Z S=-2.0)$ and hyperplasia of endocrine gland $(O P=5.4 \mathrm{E}-03, Z S=-2.0)$. Potential upstream regulators of the differently expressed genes included CCAAT/enhancer binding protein alpha (CEBPA; $O P=5.9 \mathrm{E}-03, Z S=2.5), \mathrm{KLF} 15(O P=6.2 \mathrm{E}-04, Z S$ $=2.1)$, and PPARG $(O P=8.1 \mathrm{E}-04, Z S=2.1)$ with predicted increased activity; mitogen-activated protein kinase $4(O P=1.8 \mathrm{E}-02, Z S=-2.4)$, insulin-induced gene $1(O P=2.4 \mathrm{E}-02, Z S=-2.2)$, EHHADH $(O P=$ $3.9 \mathrm{E}-05, Z S=-2.0)$, and HSD17B4 $(O P=1.7 \mathrm{E}-04, Z S$ $=-2.0)$ with predicted decreased activity.

The most significant canonical pathways included urea cycle $(O P=1.9 \mathrm{E}-04$; transcripts: $A R G 2, A S L$, $A S S 1)$, myo-inositol biosynthesis $(O P=1.3 \mathrm{E}-03$; transcripts: IMPA1, IMPA2), and superpathway of citrulline metabolism $(O P=1.9 \mathrm{E}-03$; transcripts: $A R G 2$, $A S L, A S S 1)$. The top 10 upregulated genes based on fold change and having estrous cyclic as reference group were CD36, CDKN1C, C15H11orf96, IGFBP7, ASS1, PAG2, PRUNE2, HES1, EFNA5, and CAND2, listed in decreasing order of absolute value in fold change. The top 10 downregulated genes based on fold change and having estrous cyclic as reference were $A Q P 3, S L$ C38A11, FOLR1, PDGFRA, JAM2, RNPC3, INPP 4B, TTC14, PPIF, and PHF17, listed in decreasing order of absolute value in fold change.

Using the same list of differently expressed transcripts comparing anovular against estrous cyclic, we removed the 85 transcripts previously described to be related to conceptus elongation from tubular to filamentous transition (Ribeiro et al., 2016) and reran the functional analyses to search for differences in transcriptome and associated cell biology not directly related to elongation. This analysis comprised 248 transcripts differently expressed between anovular (HA) and estrous cyclic $(\mathrm{HC}+\mathrm{CC})$. From those transcripts, 131 were upregulated and 117 were downregulated in conceptuses from anovular cows.

The main molecular and cellular functions associated with this set of genes were cellular assembly and organization (29 transcripts; $O P<0.04)$, cellular function and maintenance (32 transcripts; $O P<0.04$ ), and lipid metabolism (27 transcripts; $O P<0.04)$. Among these categories, specific function annotations with predicted increased activity included invasion of tumor cell lines $(O P=2.8 \mathrm{E}-02, Z S=2.3)$, and invasion of prostate cancer cell lines $(O P=1.1 \mathrm{E}-03, Z S=2.2)$. Specific function annotations with predicted decreased activity included glucose tolerance $(O P=2.4 \mathrm{E}-02, Z S=$ $-2.0)$. Potential upstream regulators of the differently 
expressed genes included choriogonadotropin $(O P=$ $3.9 \mathrm{E}-02, Z S=2.6)$ and CEBPA $(O P=3.6 \mathrm{E}-02, Z S$ $=2.1$ ), both with predicted increased activity in HA compared with estrous cyclic cows.

The most significant canonical pathways included myo-inositol biosynthesis $(O P=8.2 \mathrm{E}-04$; transcripts: $I M P A 1, I M P A 2)$, p53 signaling $(O P=9.9 \mathrm{E}-04$; transcripts: AKT2, CASP6, FAS, GSK3B, SERPINE2, $S F N)$, autophagy $(O P=2.6 \mathrm{E}-03$; transcripts: $A T G 4 A$, $A T G 4 D, L A M P 1, V P S 18)$, pentose phosphate pathway (nonoxidative branch) $(O P=4.0 \mathrm{E}-03$; transcripts: $R P E, R P I A), G \beta$ gamma signaling $(O P=5.4 \mathrm{E}-03$; transcripts: AKT2, CAV2, GNA15, GNAS, GNG10), DNA damage-induced $14-3-3$ signaling $(O P=1.4 \mathrm{E}-$ 02; transcripts: AKT2, GSK3B, SFN, TUBA4A, TUBB2B), signaling by Rho family GTPases $(O P=$ 2.4E-02; transcripts: ARHGEF5, CDC42EP3, GNA15, GNAS, GNG10, PIP5K1A, SEPT8), Wnt/ $\beta$-catenin signaling $(O P=2.7 \mathrm{E}-02$; transcripts: $A K T 2$, GJA1, GSK3B, TGFBR3, WNT2B). The top 10 upregulated genes based on fold change and having estrous cyclic as reference were CD36, EFNA5, CAND2, KRT6A, TPM2, TMC6, HEYL, NR2F2, PODXL, and IRS1, listed in decreasing order of absolute value in fold change. The top 10 downregulated genes based on fold change and having estrous cyclic as reference were FOLR1, RNPC3, TTC14, PHF17, TUBA4A, NR3C2, MARCKS, CDC42EP3, TSPAN5, and QTRT1 listed in decreasing order of absolute value in fold change.

Metabolomics of Uterine Fluid. In the negative ion mode, 28 features in the uterine flushing were identified to have different abundances among the 3 groups (Table 4; Supplementary Figure S1B; http://dx.doi. org/10.3168/jds.2015-10315). Peak intensities from 12 features differed between HC and HA, of which 7 had increased and 5 decreased abundance in the HA group. Another 15 features differed between $\mathrm{HC}$ and CC, of which 8 had increased and 7 decreased abundance in the $\mathrm{CC}$ group. All features identified in negative ion mode are listed in Supplementary Table S2A (http:// dx.doi.org/10.3168/jds.2015-10315) with the mean value of peak intensities and standard error of the mean for each experimental group.

In the positive ion mode, 24 features in the uterine flushing were identified to have different abundances among the 3 groups (Table 5; Supplementary Figure S1B; http://dx.doi.org/10.3168/jds.2015-10315. Peak intensities from 10 features differed between $\mathrm{HC}$ and HA and all were increased in the HA group. Another 10 features differed between $\mathrm{HC}$ and $\mathrm{CC}$, of which 5 had increased and 5 decreased abundance in the CC group. All features identified in positive ion mode are listed in Supplementary Table S2B (http://dx.doi.org/10.3168/ jds.2015-10315) with the mean value of peak intensities and standard error of the mean for each experimental group.

\section{DISCUSSION}

The fertility data from the field study presented reinforce that Holstein/Jersey crossbred cows have greater P/AI compared with Holstein cows in grazing systems, as previously reported (Ribeiro et al., 2011). In agreement with data on P/AI, the study evaluating conceptus development showed advantages for CC compared with HC. Crossbred cows presented advanced conceptus development and there was a tendency for greater $\mathrm{P} / \mathrm{AI}$ already on $\mathrm{d} 15$. Contrary to HC cows that had some ovoid conceptuses, CC had only elongated conceptuses, which were longer and tended to secrete greater amounts of IFN- $\tau$. Secretion of IFN- $\tau$ during conceptus elongation is pivotal for coordination of endometrium biology and maintenance of a functional CL secreting progesterone, a requirement for pregnancy maintenance (Thatcher et al., 1989). Crossbred cows had greater concentrations of ovarian steroids before and after AI. Estradiol concentrations increase in the periovulatory period, and they are critical for expression of estrus, ovulation, and endometrial function that affect pregnancy (Geary et al., 2013; Jinks et al., 2013; Madsen et al., 2015). Similarly, high concentrations of progesterone during growth of the preovulatory follicle benefit pregnancy in cattle (Bisinotto et al., 2010; Wiltbank et al., 2014). In addition, the increase in progesterone concentrations after AI stimulates conceptus elongation (Lonergan and Forde, 2014), which might explain the advanced conceptus development observed in CC compared with HC. Therefore, differences in concentrations of circulating ovarian steroids might be some of the determining factors for the differences in fertility between $\mathrm{HC}$ and $\mathrm{CC}$.

The differences in concentration of steroid hormones observed between $\mathrm{HC}$ and $\mathrm{CC}$ were not associated with differences in size of the ovulatory follicle and CL, suggesting that these changes likely are not related to the number of secretory cells. Possible reasons for such differences might be a greater rate of production in crossbred than in Holstein cows; the smaller body size in crossbred cows, which results in less plasma volume; and the fact that crossbred cows produce less milk than Holsteins, which might reduce splanchnic blood flow and subsequent rate of hepatic catabolism of steroid hormones (Wiltbank et al., 2006). Regardless of the exact reason, the resulting greater concentration of progesterone before and after AI and the greater concentration of estradiol during proestrus in crossbred than Holstein cows likely have potential benefits for fertility. In addition to differences in concentration of steroids, 
Table 4. Negative ion features in the metabolomic analysis of the uterine flushing that presented distinct abundance among pregnant cows from the 3 groups $^{1}$

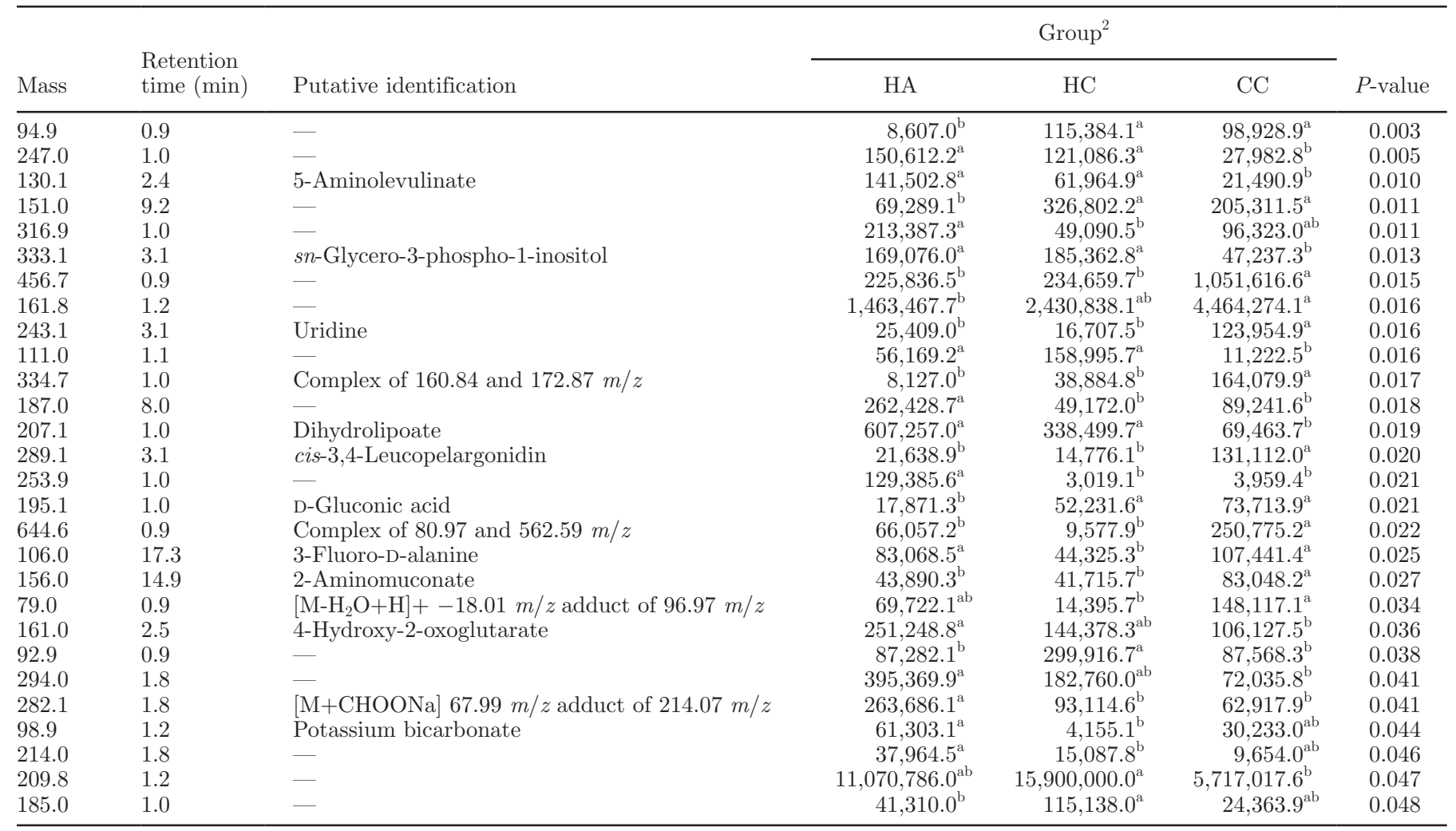

$\overline{\mathrm{a}, \mathrm{b}}$ Values with different superscripts differ $(P<0.05)$ according to Fisher's LSD in post hoc analysis from MetaboAnalyst 2.0 (http://www. metaboanalyst.ca/).

${ }^{1}$ Data presented are the LSM of peak intensities.

${ }^{2} \mathrm{HA}=$ Holstein anovular; $\mathrm{HC}=$ Holstein cyclic; $\mathrm{CC}=$ crossbred cyclic. Estrous cyclicity was determined based on the presence of a corpus luteum in 1 of 2 ultrasound examinations of the ovaries $10 \mathrm{~d}$ apart, with the second examination on the day of the first GnRH of the Ovsynch protocol.

CC also had reduced concentration of insulin in plasma compared with $\mathrm{HC}$, which might indicate a potential difference in their glycemic control. The BCS and the change in body condition in the first 39 DIM in cows of these 2 groups were similar, and IGF-1 did not change between $\mathrm{HC}$ and $\mathrm{CC}$, thereby suggesting similar energy status. Less insulin under similar energy status might benefit oocyte quality in cows (Adamiak et al., 2005).

Analyses of the transcriptome of conceptus cells and metabolomics of uterine flush fluid resulted in differences between $\mathrm{CC}$ and $\mathrm{HC}$ that might be important for conceptus development and perhaps help explain the distinctive fertility in these 2 groups of cows. Conceptus cells from CC presented greater transcript expression of PPAR $\gamma$, which is a ligand-dependent transcriptional factor thought to be important in preimplantation conceptus elongation in cattle (Ribeiro et al., 2016). Comparison of conceptus cells at different stages of elongation showed a gradual increase in transcript expression of PPAR $\gamma$ and several other genes with puta- tive PPAR response element in their regulatory regions. Most of these genes are related to lipid metabolism, which seems to be important for conceptus elongation in cattle. In fact, lipids and lipid derivatives constitute an important component of uterine histotroph during the onset of conceptus elongation and might function as natural ligands for PPAR $\gamma$ in conceptus cells (Ribeiro et al., 2016).

Cyclic crossbred cows had a greater abundance of anandamide in the uterine flush fluid than did HC. Anandamide is an endocannabinoid biosynthesized from membrane phosphatidylethanolamine (Wang and Ueda, 2009), and it has been shown to be more abundant in the histotroph of pregnant compared with nonpregnant cows (Ribeiro et al., 2016). In rodents and humans, anandamide has been implicated in important events in blastocyst activation, onset of implantation, synchrony of these 2 events, and risk of abortion (Wang et al., 2003; Wang and Dey, 2005; Rapino et al., 2014). Most of the effects of anandamide are mediated by 
binding to membrane receptors, which do not seem to be expressed by conceptus cells at this stage. Nonetheless, anandamide has also been demonstrated to act through PPAR $\gamma$ (O'Sullivan, 2007; Sun and Bennett, 2007), which again might be important for elongation of the conceptus. Moreover, the breakdown of anandamide generates arachidonic acid, which can be used for prostaglandin biosynthesis or incorporated into cell membranes.

Estrous cyclicity influenced P/AI of grazing dairy cows, regardless of the breed of the cow. Considering the difference in $\mathrm{P} / \mathrm{AI}$, it was initially predicted that HA would have poorly developed conceptuses. In contrast, d 15 conceptuses from HA were longer and secreted greater amounts of IFN- $\tau$ than conceptuses from HC. Nonetheless, the transcriptome of the conceptus cells had considerable differences and HA cows had reduced concentrations of IGF-1 in plasma compared with $\mathrm{HC}$ cows. A reasonable explanation for the difference in conceptus size between $\mathrm{HC}$ and $\mathrm{HA}$ is the distinct concentrations of progesterone in those 2 groups of cows. By design, HA had lesser concentrations of progesterone at the first $\mathrm{GnRH}$ of the synchronization program because of the lack of $\mathrm{CL}$, whereas $\mathrm{HC}$ cows had at least one CL in their ovaries. The difference in progesterone concentrations between $\mathrm{HA}$ and $\mathrm{HC}$ cows remained throughout the growth of the preovulatory follicle. Less progesterone allows greater secretion of gonadotropins and accelerated development of the dominant follicle, resulting in ovulation of a larger follicle and, therefore, a larger CL. The consequence of a larger CL is increased progesterone concentrations in the postovulatory period, which hastens conceptus elongation (Lonergan and Forde, 2014).

Although the conceptuses used for transcriptome analysis were all elongated and morphologically similar among the 3 groups, those from HA were still larger than those from the HC group, and it is possible that some of the differences between anovular and estrous cyclic cows were caused by the accelerated rate of conceptus development in HA compared with HC. In fact, 87 transcripts differently expressed between HA and $\mathrm{HC}$ were common to differences between tubular (5 to $19 \mathrm{~mm}$ ) and filamentous (20 to $60 \mathrm{~mm}$ ) conceptuses reported by Ribeiro et al. (2016). These transcripts included genes that are considered important

Table 5. Positive ion features in the metabolomic analysis of the uterine flushing that presented distinct abundance among pregnant cows from the 3 groups $^{1}$

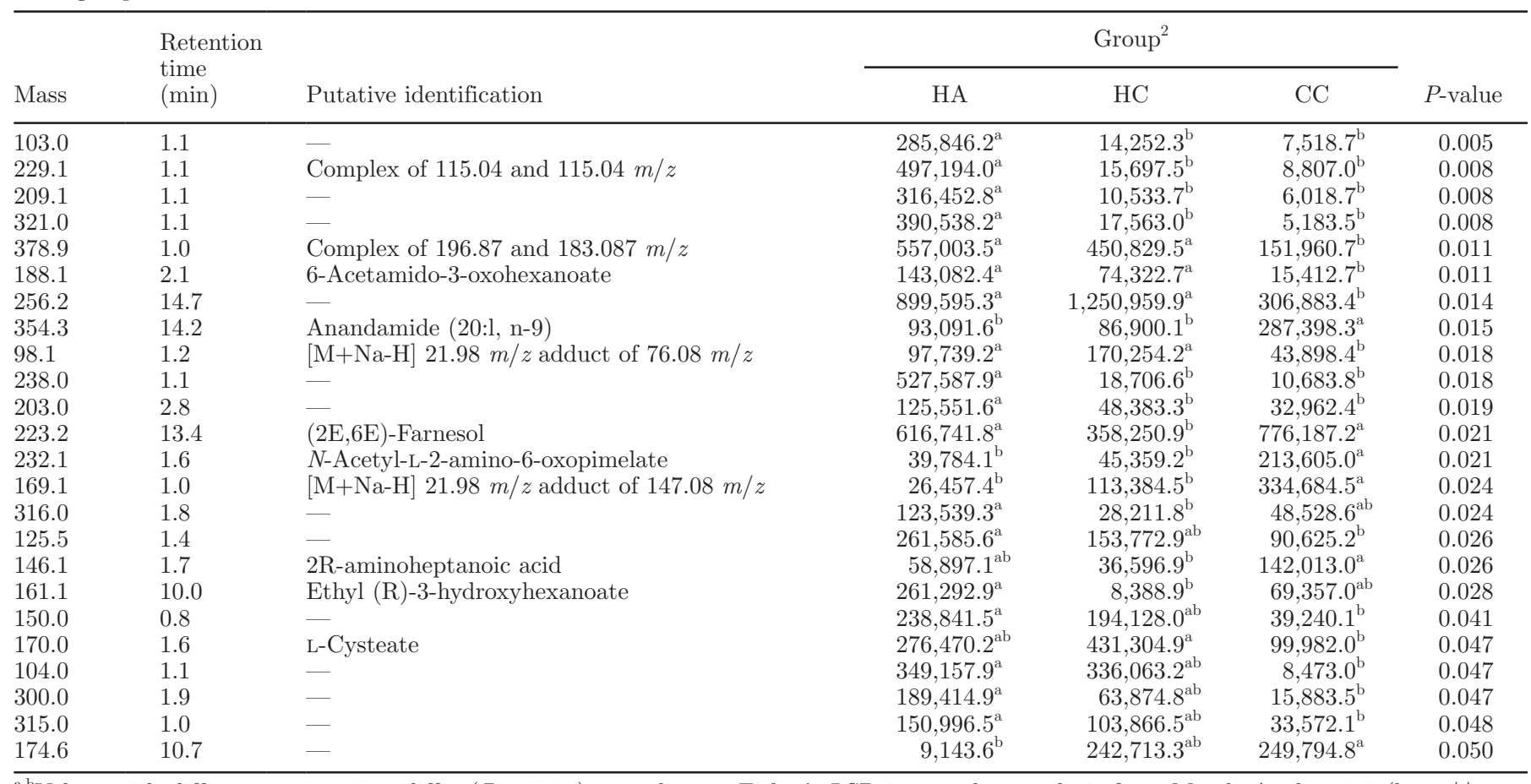

\footnotetext{
${ }^{\mathrm{a}, \mathrm{b}}$ Values with different superscripts differ $(P<0.05)$ according to Fisher's LSD in post hoc analysis from MetaboAnalyst 2.0 (http://www. metaboanalyst.ca/).

${ }^{1}$ Data presented are the LSM of peak intensities.

${ }^{2} \mathrm{HA}=$ Holstein anovular; $\mathrm{HC}=$ Holstein cyclic; $\mathrm{CC}=$ crossbred cyclic. Estrous cyclicity was determined based on the presence of a corpus luteum in 1 of 2 ultrasound examinations of the ovaries $10 \mathrm{~d}$ apart, with the second examination on the day of the first GnRH of the Ovsynch protocol.
} 
for conceptus elongation, such as PPARG, SLC10A1, PEX11A, ACOX1, CRAT, AGPAT3, ASS1, ASL, and PAG2, among others (Ribeiro et al., 2016), and they were all increased in HA compared with HC. Nonetheless, 413 other transcripts were differently expressed between the 2 groups of cows that were unrelated to the transition from tubular to filamentous stage. These differences might help explain the diverging fertility between anovular and estrous cyclic cows.

Based on the aforementioned findings, we could hypothesize that developmental problems in anovular cows occur before d 15 and the conceptuses that survived by d 15 would continue to develop comparably to conceptuses in estrous cyclic cows. In favor of this hypothesis is the phenotype of the conceptus and increased secretion of IFN- $\tau$. On the contrary, one could suggest that although HA conceptuses were longer and secreted more IFN- $\tau$, they might not necessarily be better, and perhaps the difference in transcriptome could indicate imbalances in cell biology that could result in greater incidence of pregnancy loss after d 15. In support of the latter, research has demonstrated increased pregnancy loss in anovular cows (Santos et al., 2004) and in those that develop the ovulatory follicle under low concentrations of progesterone (Bisinotto et al., 2010), and supplementing progesterone to anovular cows increases $\mathrm{P} / \mathrm{AI}$ and reduces pregnancy loss (Bisinotto et al., 2015). The large number of differently expressed genes observed in HA compared with HC suggests metabolic differences that might be linked to the increased risk of pregnancy failure.

Insulin-like growth factor 1 is important for conceptus development in cattle, especially during elongation. It is an upstream regulator that coordinates changes in gene expression of conceptus cells during elongation, and it is associated positively with the amount of IFN- $\tau$ secreted by the conceptus and with conceptus survival in lactating dairy cows (Ribeiro et al., 2014; 2016). The main downstream effects of IGF-1 are stimulation of cell proliferation and survival, and signaling is mediated through phosphatidylinositol and v-akt murine thymoma viral oncogene (AKT; Siddle, 2011). Interestingly, conceptuses from HA had reduced expression of IMPA1, IMPA2, PIP5K1A, and AKT2, all of which are important for phosphatidylinositol/AKT signaling. Both IGF-1 and insulin receptors activate phosphatidylinositol signaling, which in turn activates AKT signaling that interacts with several other proteins to coordinate energy metabolism, cell survival, proliferation, and migration. One of the downstream targets of AKT is the mechanistic target of rapamycin (mTOR) signaling, which has been demonstrated to be needed for elongation of preimplantation ovine conceptuses
(Kim et al., 2010). Therefore, the reduced concentration of IGF-1 combined with reduced expression of key enzymes of the phosphatidylinositol/AKT signaling pathway might have negative consequences for cell survival and proliferation in conceptuses of HA cows.

The functional analysis of transcriptome data pointed to differences in canonical pathways related to apoptosis, 14-3-3 signaling, and autophagy. In fact, p53 signaling was predicted to be increased in HA conceptuses. Protein p53 has a central role in sensing cellular stress and controlling cellular processes such as cell cycle progression, autophagy, and apoptosis (Brady and Attardi, 2010). The prediction of increased activity of p53 in HA was linked to the increased expression of genes such as CASP6, SFN, DAP, GSK3B, LAMP1, and ATG4A, and the reduced expression of $A K T 2$. Caspase 6 (CASP6) is an executioner caspase that functions as an endoprotease regulating apoptosis (McIlwain et al., 2013) and has been suggested to be important in early (Little et al. 2003) and late embryo development (Godefroy et al., 2013) in mice. The p53 protein interacts with the CASP6 promoter, working as a transcription activator to increase expression and activity of CASP6 (Yang et al., 2008; Ehrnhoefer et al., 2014). In fact, expression of CASP 6 reduces the threshold for apoptosis and is considered the most downstream component of the apoptosis pathway induced by p53 (MacLachlan and El-Deiry, 2002).

Another pro-apoptotic protein that had increased transcript expression in HA conceptuses is glycogen synthase kinase $3 \beta$ (GSK3B). When active, this protein inhibits a series of transcription factors associated with cell survival (Grimes and Jope, 2001). Interestingly, p53 is known to stimulate its activity, whereas AKT is known to inhibit its activity (Grimes and Jope, 2001; Watcharasit et al., 2002). In fact, part of the cell survival effects of AKT signaling is mediated through inhibition of GSK3 $\beta$. Thus, not only was the transcript expression of $G S K 3 B$ increased in HA but its activity was predicted to be increased considering the potential increase in activity of p53 and reduced expression of AKT2 in HA conceptuses. Extensive apoptosis of conceptus cells is an event generally assumed to precede embryonic mortality and pregnancy loss (Toder et al., 2002). Therefore, upregulation of genes involved in apoptosis in HA conceptuses on d 15 might favor pregnancy loss later in development.

Autophagy was another canonical pathway predicted to be affected by estrous cyclicity and was linked to the differential expression of genes such as $A T G 4 A$, MAP1LC3B, LAMP1, ATG4D, and VPS18. The first 3 genes had increased expression and the latter 2 genes had decreased expression in HA compared with 
HC. Both autophagy-related 4 homolog A $(A T G 4 A)$ and microtubule-associated protein 1 light chain $3 \beta$ (MAP1LC3B) encode proteins involved in the biogenesis of autophagosomes (Reggiori, 2006). Moreover, lysosomal-associated membrane protein 1 (LAMP1) is a transmembrane glycoprotein located mostly in the lysosome membrane and responsible for regulating the fusion of lysosomes with autophagosomes, a process critical for the enzymatic degradation of cytoplasmic materials in the autophagosomes for recycling of nutrients (Saftig and Klumperman, 2009). Thus, the increased expression of these 3 genes suggests an increased rate of autophagy in HA conceptuses. Cells use autophagy during stress such as nutrient deprivation or to eliminate aberrant protein aggregates and malfunctioning organelles (Saftig and Klumperman, 2009). Nevertheless, autophagy can induce apoptosis in a process dependent on caspase activity (Scott et al., 2007). Interestingly, HA conceptuses had increased transcript expression of death-associated protein 1 (DAP1), another protein considered to be pro-apoptotic but whose activity was demonstrated to regulate the rate of autophagy by interacting with mTOR signaling in a "gas/brake" model (Koren et al., 2010) and to prevent overactivation of autophagy under nutrient deprivation or reduced mTOR signaling.

Energy metabolism is certainly critical for conceptus development, and anovular cows normally suffer from more severe negative nutrient balance postpartum compared with estrous cyclic cows that ultimately causes delayed resumption of estrous cyclicity (Butler, 2003). The impaired energy balance in anovular cows results in a legacy of events that perpetuate to the time of breeding and early embryo development, therefore potentially affecting early conceptus development and placentation. Nonetheless, it is important to point out that the low concentration of progesterone during ovulatory follicle development has been identified as a major cause of reduced fertility in anovular cows (Bisinotto et al., 2010; Wiltbank et al., 2014). Estrous cyclic cows induced to ovulate a follicle that develops under low concentrations of progesterone, mimicking the endocrine milieu observed in anovular cows, had a similar reduction in $\mathrm{P} / \mathrm{AI}$ as that observed in anovular cows (Bisinotto et al., 2010). Moreover, progesterone supplementation during ovulatory follicle development was able to rescue $\mathrm{P} / \mathrm{AI}$ in anovular or low progesterone cows (Bisinotto et al., 2013). It is noteworthy that only anovular cows that do not express estrus at AI presented reduced $\mathrm{P} / \mathrm{AI}$. This finding reinforces that events occurring before ovulation have remarkable effects in developmental biology during early pregnancy. Whether the reduced fertility in anovular compared with estrous cyclic cows is mediated through the oocyte quality and its developmental competence or through carryover effects on the uterus and its capacity to support pregnancy survival or both is unknown and remains to be investigated.

\section{CONCLUSIONS}

Holstein/Jersey crossbred cows presented improved conceptus development on d 15 of development compared with Holstein cows. Conceptuses on d 15 from crossbred cows were longer, tended to secrete greater amounts of IFN- $\tau$, and had greater expression of PPAR $\gamma$, an important transcription factor that coordinates lipid metabolism and elongation at preimplantation development. Moreover, crossbred cows had greater concentrations of anandamide in the uterine flush fluid, which might be important for activation of PPAR $\gamma$ and for later coordination of implantation. Crossbred cows had greater concentrations of progesterone and estradiol in plasma with similar size CL and follicles, which suggest that these ovarian steroids during the periestrual period and early gestation are likely causative factors for improved fertility. In addition, differences in metabolic hormones observed in the current study might influence conceptus development. It is suggested that the differences in fertility observed between these 2 genetic groups are mediated by changes in metabolic and ovarian steroid hormones that influence conceptus development during the preimplantation period. Estrous cyclicity at the initiation of synchronization had a large effect on $\mathrm{P} / \mathrm{AI}$ of grazing dairy cows, and this difference was observed in those that did not display signs of estrus at AI. Interestingly, d-15 conceptuses from anovular cows were longer and secreted greater amounts of IFN- $\tau$ than conceptuses from estrous cyclic cows, likely a consequence of the different concentrations of progesterone in these 2 groups of cows. Anovular cows had lesser concentrations of progesterone during ovulatory follicle development, resulting in a larger ovulatory follicle that, in turn, resulted in the formation of a larger CL and more progesterone that anticipated conceptus elongation compared with estrous cyclic cows. Nonetheless, anovular cows had reduced concentrations of IGF1 in plasma and their conceptuses presented remarkable differences in the transcriptome. Some of the altered transcripts in conceptus cells from anovular cows indicate greater cellular stress and increased apoptosis and autophagy, which could influence subsequent survival of the pregnancy past d 15 of development. Nonetheless, further research is needed to understand the alterations in early developmental biology in anovular cows after induced ovulation. 


\section{ACKNOWLEDGMENTS}

Authors thank the owners and staff of Piedmont dairy (Trenton, FL) for use of their cows in this project. Our appreciation is extended to Accelerated Genetics (Baraboo, WI) for providing the semen used for insemination of cows in the conceptus collection study. The authors thank Yanping Zhang (Interdisciplinary Center for Biotechnology Research, University of Florida, Gainesville) and Timothy Garrett (Southeast Center for Integrated Metabolomics, University of Florida, Gainesville) for assistance with the with the transcriptome and metabolome assays. Partial funding for this project was provided by the National Institute of Food and Agriculture (Washington, DC; Grant No. 2015-67015-23313).

\section{REFERENCES}

Adamiak, S. J., K. Mackie, R. G. Watt, R. Webb, and K. D. Sinclair. 2005. Impact of nutrition on oocyte quality: Cumulative effects of body composition and diet leading to hyperinsulinemia in cattle. Biol. Reprod. 73:918-926.

Benjamini, Y., and Y. Hochberg. 1995. Controlling the false discovery rate - A practical and powerful approach to multiple testing. J. R. Stat. Soc. B Stat. Methodol. 57:289-300.

Bisinotto, R. S., R. C. Chebel, and J. E. P. Santos. 2010. Follicular wave of the ovulatory follicle and not cyclic status influences fertility of dairy cows. J. Dairy Sci. 93:3578-3587.

Bisinotto, R. S., I. J. Lean, W. W. Thatcher, and J. E. P. Santos. 2015. Meta-analysis of progesterone supplementation during timed artificial insemination programs in dairy cows. J. Dairy Sci. 98:24722487.

Bisinotto, R. S., E. S. Ribeiro, F. S. Lima, N. Martinez, L. F. Greco, L. F. S. P. Barbosa, P. P. Bueno, L. F. S. Scagion, W. W. Thatcher, and J. E. P. Santos. 2013. Targeted progesterone supplementation improves fertility in lactating dairy cows without a corpus luteum at the initiation of the timed artificial insemination protocol. J. Dairy Sci. 96:2214-2225.

Brady, C. A., and L. D. Attardi. 2010. p53 at a Glance. J. Cell Sci. 123:2527-2532.

Butler, W. R. 2003. Energy balance relationships with follicular development, ovulation and fertility in postpartum dairy cows. Livest. Prod. Sci. 83:211-218.

Egger-Danner, C., J. B. Cole, J. E. Pryce, N. Gengler, B. Heringstad, A. Bradley, and K. F. Stock. 2015. Invited review: Overview of new traits and phenotyping strategies in dairy cattle with a focus on functional traits. Animal 9:191-207.

Ehrnhoefer, D. E., N. H. Skotte, S. Ladha, Y. T. N. Nguyen, X. Qiu, Y. Deng, K. T. Huynh, S. Engemann, S. M. Nielsen, K. Becanovic, B. R. Leavitt, L. Hasholt, and M. R. Hayden. 2014. p53 increases caspase-6 expression and activation in muscle tissue expressing mutant huntingtin. Hum. Mol. Genet. 23:717-729.

Ferguson, J. D., D. T. Galligan, and N. Thomsen. 1994. Principal descriptors of body condition score in Holstein cows. J. Dairy Sci. 77:2695-2703.

Geary, T. W., M. F. Smith, M. D. MacNeil, M. L. Day, G. A. Bridges, G. A. Perry, F. M. Abreu, J. A. Atkins, K. G. Pohler, E. M. Jinks, and C. A. Madsen. 2013. Influence of follicular characteristics at ovulation on early embryonic survival. J. Anim. Sci. 91:3014-3021.

Godefroy, N., B. Foveau, S. Albrecht, C. G. Goodyer, and A. C. LeBlanc. 2013. Expression and activation of caspase-6 in human fetal and adult tissues. PLoS ONE 8:e79313.

Grimes, C. A., and R. S. Jope. 2001. The multifaceted roles of glycogen synthase kinase $3 \beta$ in cellular signaling. Prog. Neurobiol. 65:391-426.
Heins, B. J., L. B. Hansen, A. J. Seykora, D. G. Johnson, J. G. Linn, J. E. Romano, and A. R. Hazel. 2008. Crossbreds of Jersey $\times$ Holstein compared with pure Holsteins for production, fertility, and body and udder measurements during first lactation. J. Dairy Sci. 91:1270-1278.

Jinks, E. M., M. F. Smith, J. A. Atkins, K. G. Pohler, G. A. Perry, M. D. MacNeil, A. J. Roberts, R. C. Waterman, L. J. Alexander, and T. W. Geary. 2013. Preovulatory estradiol and the establishment and maintenance of pregnancy in suckled beef cows. J. Anim. Sci. 91:1176-1185.

Kim, J., D. W. Erikson, R. C. Burghardt, T. E. Spencer, G. Wu, K. J. Bayless, G. A. Johnson, and F. W. Bazer. 2010. Secreted phosphoprotein 1 binds integrins to initiate multiple cell signaling pathways, including FRAP1/mTOR, to support attachment and force-generated migration of trophectoderm cells. Matrix Biol. $29: 369-382$

Koren, I., E. Reem, and A. Kimchi. 2010. DAP1, a novel substrate of mTOR, negatively regulates autophagy. Curr. Biol. 20:1093-1098.

Krämer, A., J. Green, J. Pollard Jr., and S. Tugendreich. 2014. Causal analysis approaches in Ingenuity Pathway Analysis. Bioinformatics 30:523-530.

Little, S. A., W. K. Kim, and P. E. Mirkes. 2003. Teratogen-induced activation of caspase- 6 and caspase- 7 in early postimplantation mouse embryos. Cell Biol. Toxicol. 19:215-226.

Lonergan, P., and N. Forde. 2014. Maternal-embryo interaction leading up to the initiation of implantation of pregnancy in cattle. Animal 8(Suppl. 1):64-69.

MacLachlan, T. K., and W. S. El-Deiry. 2002. Apoptotic threshold is lowered by p53 transactivation of caspase-6. Proc. Natl. Acad. Sci. USA 99:9492-9497.

Madsen, C. A., G. A. Perry, C. L. Mogck, R. F. Daly, M. D. MacNeil, and T. W. Geary. 2015. Effects of preovulatory estradiol on embryo survival and pregnancy establishment in beef cows. Anim. Reprod. Sci. 158:96-103.

McDougall, S., F. M. Rhodes, and G. A. Verkerk. 2005. Pregnancy loss in dairy cattle in the Waikato region of New Zealand. N. Z. Vet. J. 53:279-287.

McIlwain, D. R., T. Berger, and T. W. Mak. 2013. Caspase functions in cell death and disease. Cold Spring Harb. Perspect. Biol. 5:a008656.

O'Sullivan, S. E. 2007. Cannabinoids go nuclear: Evidence for activation of peroxisome proliferator-activated receptors. Br. J. Pharmacol. 152:576-582.

Pluskal, T., S. Castillo, A. Villar-Briones, and M. Orešič. 2010. MZmine 2: Modular framework for processing, visualizing, and analyzing mass spectrometry-based molecular profile data. BMC Bioinformatics 11:395.

Rapino, C., N. Battista, M. Bari, and M. Maccarrone. 2014. Endocannabinoids as biomarkers of human reproduction. Hum. Reprod. Update 20:501-516.

Reggiori, F. 2006. Membrane origin for autophagy. Curr. Top. Dev. Biol. 74:1-30.

Rhodes, F. M., S. McDougall, C. R. Burke, G. A. Verkerk, and K. L. Macmillan. 2003. Treatment of cows with an extended postpartum anestrous interval. J. Dairy Sci. 86:1876-1894.

Ribeiro, E. S., R. G. S. Bruno, A. M. Farias, J. A. Hernández-Rivera G. C. Gomes, R. Surjus, G. Sasser, D. H. Keisler, W. W. Thatcher, T. R. Bilby, and J. E. P. Santos. 2014. Low doses of bovine somatotropin enhance conceptus development and fertility in lactating dairy cows. Biol. Reprod. 90:10.

Ribeiro, E. S., R. L. A. Cerri, R. S. Bisinotto, F. S. Lima, F. T. Silvestre, M. G. Favoreto, L. F. Greco, W. W. Thatcher, and J. E. P. Santos. 2011. Reproductive performance of grazing dairy cows following presynchronization and resynchronization protocols. J. Dairy Sci. 94:4984-4996.

Ribeiro, E. S., L. F. Greco, R. S. Bisinotto, F. S. Lima, W. W. Thatcher, and J. E. P. Santos. 2016. Biology of preimplantation conceptus at the onset of elongation in dairy cows. Biol. Reprod. http:// dx.doi.org/10.1095/biolreprod.115.134908.

Ribeiro, E. S., A. P. A. Monteiro, F. S. Lima, H. Ayres, R. S. Bisinotto, M. Favoreto, L. F. Greco, R. S. Marsola, W. W. Thatcher, 
and J. E. P. Santos. 2012. Effects of presynchronization and length of proestrus on fertility of grazing dairy cows subjected to a 5-day timed artificial insemination protocol. J. Dairy Sci. 95:2513-2522.

Rodina, T. M., F. N. T. Cooke, P. J. Hansen, and A. D. Ealy. 2009 Oxygen tension and medium type actions on blastocyst development and interferon-tau secretion in cattle. Anim. Reprod. Sci. 111:173-188.

Saftig, P., and J. Klumperman. 2009. Lysosome biogenesis and lysosomal membrane proteins: Trafficking meets function. Nat. Rev Mol. Cell Biol. 10:623-635.

Santos, J. E. P., H. M. Rutigliano, and M. F. Sá Filho. 2009. Risk factors for resumption of postpartum cyclicity and embryonic survival in lactating dairy cows. Anim. Reprod. Sci. 110:207-221.

Santos, J. E. P., W. W. Thatcher, R. C. Chebel, R. L. A. Cerri, and K. N. Galvão. 2004. The effect of embryonic death rates in cattle on the efficacy of estrus synchronization programs. Anim. Reprod. Sci. 82-83:513-535.

Scott, R. C., G. Juhasz, and T. P. Neufeld. 2007. Direct induction of autophagy by Atg1 inhibits cell growth and induces apoptotic cell death. Curr. Biol. 17:1-11.

Siddle, K. 2011. Signalling by insulin and IGF receptors: Supporting acts and new players. J. Mol. Endocrinol. 47:R1-R10.

Smyth, G. K. 2004. Linear models and empirical Bayes methods for assessing differential expression in microarray experiments. Stat. Appl. Genet. Mol. Biol. 3:3.

Smyth, G. K. 2005. Limma: Linear models for microarray data. Pages 397-420 in Bioinformatics and Computational Biology Solutions using R and Bioconductor. R. Gentleman, V. Carey, S. Dudoit, R. Irizarry, W. Huber, ed. Springer, New York, NY.

Sun, Y., and A. Bennett. 2007. Cannabinoids: A new group of agonists of PPARs. PPAR Res. 2007:23513.

Thatcher, W. W., P. J. Hansen, T. S. Gross, S. D. Helmer, C. Plante, and F. W. Bazer. 1989. Antiluteolytic effects of bovine trophoblast protein-1. J. Reprod. Fertil. Suppl. 37:91-99.

Toder, V., H. Carp, A. Fein, and A. Torchinsky. 2002. The role of pro- and anti-apoptotic molecular interactions in embryonic maldevelopment. Am. J. Reprod. Immunol. 48:235-244.
Wang, H., and S. K. Dey. 2005. Lipid signaling in embryo implantation. Prostaglandins Other Lipid Mediat. 77:84-102

Wang, H., H. Matsumoto, Y. Guo, B. C. Paria, R. L. Roberts, and S. K. Dey. 2003. Differential G protein-coupled cannabinoid receptor signaling by anandamide directs blastocyst activation for implantation. Proc. Natl. Acad. Sci. USA 100:14914-14919.

Wang, J., and N. Ueda. 2009. Biology of endocannabinoid synthesis system. Prostaglandins Other Lipid Mediat. 89:112-119.

Watcharasit, P., G. N. Bijur, J. W. Zmijewski, L. Song, A. Zmijewska, X. Chen, G. V. W. Johnson, and R. S. Jope. 2002. Direct, activating interaction between glycogen synthase kinase-3 3 and p53 after DNA damage. Proc. Natl. Acad. Sci. USA 99:7951-7955.

Weigel, K. A., and K. A. Barlass. 2003. Results of a producer survey regarding crossbreeding on us dairy farms. J. Dairy Sci. 86:4148 4154 .

Wiltbank, M. C., A. Gümen, and R. Sartori. 2002. Physiological classification of anovulatory conditions in cattle. Theriogenology $57: 21-52$

Wiltbank, M. C., H. Lopes, R. Sartori, S. Sangsritavong, and A. Gümen. 2006. Changes in reproductive physiology of lactating dairy cows due to elevated steroid metabolism. Theriogenology 65:17-29.

Wiltbank, M. C., A. H. Souza, P. D. Carvalho, A. P. Cunha, J. O. Giordano, P. M. Fricke, G. M. Baez, and M. G. Diskin. 2014. Physiological and practical effects of progesterone on reproduction in dairy cattle. Animal 8(Suppl. 1):70-81.

Wu, Z., R. A. Irizarry, R. Gentleman, F. Martinez-Murillo, and F. Spencer. 2004. A model-based background adjustment for oligonucleotide expression arrays. J. Am. Stat. Assoc. 99:909-917.

Xia, J., R. Mandal, I. V. Sinelnikov, D. Broadhurst, and D. S. Wishart. 2012. MetaboAnalyst 2.0-A comprehensive server for metabolomic data analysis. Nucleic Acids Res. 40(Web Server Issue):W127-133.

Yang, C., V. Kaushal, R. S. Haun, R. Seth, S. V. Shah, and G. P. Kausha. 2008. Transcriptional activation of caspase- 6 and -7 genes by cisplatin-induced p53 and its functional significance in cisplatin nephrotoxicity. Cell Death Differ. 15:530-544. 